\title{
Katharina Krause
}

\section{Zu Zeichnungen französischer Architekten um I700}

"L'architecture et le dessin ne sont qu'une même chose «, sagt Charles Le Brun 1672 in einer Rede vor der Académie de Peinture et de Sculpture in Paris. Mit diesem Satz erkennt er die Bedeutung an, die die Zeichnung in der Architektur seiner Zeit im Prozeß des Entwerfens gewonnen hat. In der Planung für Innendekorationen, die großer zeichnerischer Fähigkeiten bedürfe, sieht er eine Hauptaufgabe der Architekten ${ }^{1}$. Das Argument, mit dem Le Brun die Gleichsetzung von Zeichnung und Architektur begründet, läßt ahnen, daß ihm die Problematik der Architekturzeichnung als eigene Gattung entgeht. Als Maler erinnert er seine Kollegen daran, daß das Zeichnen-Können die Maler und Bildhauer in Italien zu Architekten habe werde lassen. Damit macht er die Architekten als zeichnenden Berufsstand überflüssig.

Über diese Feststellungen Le Bruns hinaus konnten Bauzeichnungen außerhalb der Fachkreise der Architekten nur wenige zusätzliche Aspekte abgewonnen werden. In jüngster Zeit wurden sie gerne als Belege für die Kreativität und den Schaffensprozeß der Architekten beachtet. Das hat einen Grund sicher darin, daß Architekten des 20. Jahrhunderts die Zeichnung, gerade auch die eigenhändige Zeichnung, als reizvolle Aufgabe und als Chance sehen, Architektur als Baukunst zu legitimieren. Das Interesse konzentriert sich daher häufig auf die Skizze, das Schaubild oder den Idealentwurf, während Zeichnungen aus der Baupraxis als mechanisch wiederholbare, von subalternen Bauzeichnern ausgeführte Blätter nicht berücksichtigt werden ${ }^{2}$. Diese Haltung schließt ein Verständnis für die zeichnerischen Probleme barocker Risse in Frankreich aus, denn aus dem 17. und 18. Jahrhundert haben sich hier nur wenige Skizzen und eigenhändige Reinzeichnungen von Architekten, dafür aber um so mehr vom Personal eines Baubureaus ausgearbeitete Präsentationsrisse erhalten. Sie sind daher einzig als Dokumente über nicht mehr existente Bauten oder Quelle für Etappen in komplizierten Baugeschichten benutzt worden.
Dieser Umgang mit barocken Architekturzeichnungen setzt jedoch nur das Verhalten der Zeitgenossen fort. Im Gegensatz zu Zeichnungen von Malern und Bildhauern wurden Architekturzeichnungen im 17 . und 18 . Jahrhundert nicht gesammelt, es sei denn von den Architekten selbst. Dann wurden sie aber nur in das eigene Archiv eingeordnet und dienten als Vorlagen und Anregungen für künftige Projekte. Die umfangreichsten Sammlungen französischer Architekturzeichnungen, aus denen ich im Folgenden einen Großteil der Beispiele beziehe, entstanden auf diese Weise. Es handelt sich um das Planarchiv der Bâtiments du Roi und den damit verbundenen Nachlaß der Architektenfamilie de Cotte $^{3}$ sowie den großen schwedischen Bestand, dessen Grundstock Nikodemus Tessin legte4. Tessin erwarb bei seinem Aufenthalt in Paris zahlreiche Zeichnungen, kopierte sie oder ließ sie kopieren. Dieses Verfahren, eine Musterkollektion anzulegen, zeigt deutlich, daß Tessin nicht an der Art der Darstellung, sondern an der dargestellten Architektur interessiert war.

Es hatte also eine gewisse Berechtigung, daß Carl Linfert nur Idealentwürfe behandelte, die Zeich-

r Charles Le Brun: Discours prononcé en l'assemblée publique de l'académie royale de peinture et de sculpture, lege jour de janvier 1672, in: André Fontaine: Conférences inédites de l'Académie de Peinture, Paris 1902, 4 Iff.

2 Vgl. z. B.: Idee und Anspruch der Architektur, Zeichnungen des 16. und 17. Jahrhunderts aus dem CooperHewitt Museum, New York, Köln 1979, rof.; Winfried Nerdinger: Vom barocken Idealplan zur Axonometrie. Zeichnungen aus der Architektursammlung der Technischen Universität München, München 1985 .

${ }_{3}$ Zum Archiv der Bâtiments du Roi: Danielle GalletGuerne: Versailles. Dessins d'architecture de la Direction générale des Bâtiments du Roi, Paris 1983; zum fonds de Cotte der Bibliothèque Nationale: Pierre Marcel: Inventaire des papiers manuscrits du cabinet de Robert de Cotte et de Jules-Robert de Cotte conservés à la Bibliothèque Nationale, Paris 1906.

4 Versailles à Stockholm. Dessins du Nationalmuseum, Paris 1985, 7ff.; Oswald Sirén: Nicodemus Tessin den Ys. Studieresor, Stockholm 1914. 
nungen aus der Baupraxis, also das Gros des erhaltenen Materials aber ausließ, als er 1931 versuchte, Eigenschaften französischer Architekturzeichnungen in Abgrenzung von Handzeichnungen der Maler beschreibend zu definierens. Linfert hatte von vornherein ausgeschlossen, $\mathrm{da} ß$ diese Zeichnungen in der Auseinandersetzung mit dem Anspruch des Auftraggebers und den Bedingungen der Baupraxis eigene, fertige Lösungen bieten könnten. Er hatte sich daher vorschnell der Aufgabe entledigt, Konventionen der Bauzeichnung festzustellen, bevor er Idealentwürfe und Capricci als die einzig interessanten, weil von allen äußeren Zwängen gelösten Zeichnungen der Architekten betrachtete.

Für eine Geschichte der französischen Bauzeichnung muß man daher auf die wenig systematischen, aus der Architekturpraxis des späten 18. Jahrhunderts hervorgegangenen Notizen zurückgreifen. 1801 faßte Quatremère de Quincy die Aufgaben von Projektzeichnungen und die Entwicklung ihrer darstellerischen Techniken für die Encyclopédie méthodique zusammen: »On voit que la plûpart des anciens dessins d'architecture n'étoient que de simples traits à la plume, hachés ou lavés légèrement au bistre. Les modernes architectes semblent avoir fait un art particulier de dessiner l'architecture... Je ne prétends pas au reste attaquer ce mérite de fini dans les dessins, quoiqu’à vrai dire, le fini des dessins d'architecture consiste dans la pureté du trait, la fidélité des mesures et la précision des proportions. Je me contente de remarquer que ce mérite ne constitue pas celui de l'architecture, et qu'on peut faire sans une si grande propreté de lavis, ou sans le pittoresque, et l'effet de clairs ou des ombres nuancées, comme dans un tableau, d'aussi bons dessins d'architecture et aussi propres á l'objet principal auquel on les destine, qui est l'execution « 6 .

Die Auseinandersetzung mit den Ansprüchen der »malerischen* Zeichnung ist also eine Konstante in der Diskussion des 17. und 18. Jahrhunderts. Wie der Maler Le Brun betont Quatremère, der wenigstens gelegentlich als Architekt dilettierte, die Rolle der Zeichnung im Entwurfsverfahren. Er vermeidet aber die Gleichsetzung von
Zeichnung und Architektur und beharrt auf der Ausführung, d. h. auch der Ausführbarkeit, der Projekte. Als Grund für die Entwicklung vom mit der Feder gezeichneten Riß der »Alten « zu aquarellierten Entwurf, den er in seiner pittoresken Variante des späten I8. Jahrhunderts kennengelernt hatte, nennt Quatrèmere die Arbeitsteilung im Bauwesen in »invention* und »exécution«. Hier trifft er die Selbsteinschätzung der Architekten und ihre Abgrenzung von Ingenieuren und Bauunternehmern7. Er vergißt jedoch den Adressaten der Zeichnungen, den Bauherrn, der die »exécution« des Projekts veranlaßt.

Im folgenden soll untersucht werden, welche Konventionen für die Wahl bestimmter Darstellungsmethoden oder graphischer Mittel ausschlaggebend waren. Präsentationsrisse sollen einmal nicht als Dokumente für Architekturprojekte gelten, sondern nach dem Anspruch befragt werden, den die Architekten und die Bauherren an das Medium Architekturzeichnung stellten.

Es bietet sich an, an dem Punkt einzusetzen, an dem die von Quatremère genannten Zeichentechniken der Alten und Modernen nebeneinander existieren, in den ersten Jahrzehnten des I8. Jahrhunderts. Als Beispiel sollen die Projekte für den Hochaltar von St. Germain-des-Prés dienen, der I705 geweiht wurde ${ }^{8}$. Dem Bau dieses Altars, eines sechssäuligen Ziboriums nach Entwurf von Gilles-Marie Oppenord, war eine längere Phase der

\footnotetext{
s Carl Linfert: Die Grundlagen der Architekturzeichnung. Mit einem Versuch über französische Architekturzeichnungen des I8. Jahrhunderts, Kunstwissenschaftliche Forschungen I, 1931, 133-246.

6 Antoine-Chrysostome Quatremère de Quincy: Encyclopédie méthodique ou par ordre de matières, Architecture, Bd. 2, Paris 1802 , 209; vgl. auch Jacques-François Blondel: Cours d'architecture, Paris 1771, Bd. I, I35, Bd. 3, XXXIIff.

7 Vgl. La Formation architecturale au dix-huitième siècle en France. Rapport de recherche, Paris 1980, 37ff.; Jacques Guillerme: La figurazione in architettura, Mailand 1982, I02.

8 Vgl. Dom Jacques Bouillart: Histoire de l'abbaye royale de St. Germain des Prez, Paris r724; E. Lefèvre-Pontalis: Etude historique et archéologique sur l'Eglise de St. Germain-des-Prés, Congrès archéologique 1919, 30I366, bes. 3roff.; François Souchal: Les Slodtz, sculpteurs et décorateurs du Roi (1685-1764), Paris 1967, sorff., Taf. 78.
} 


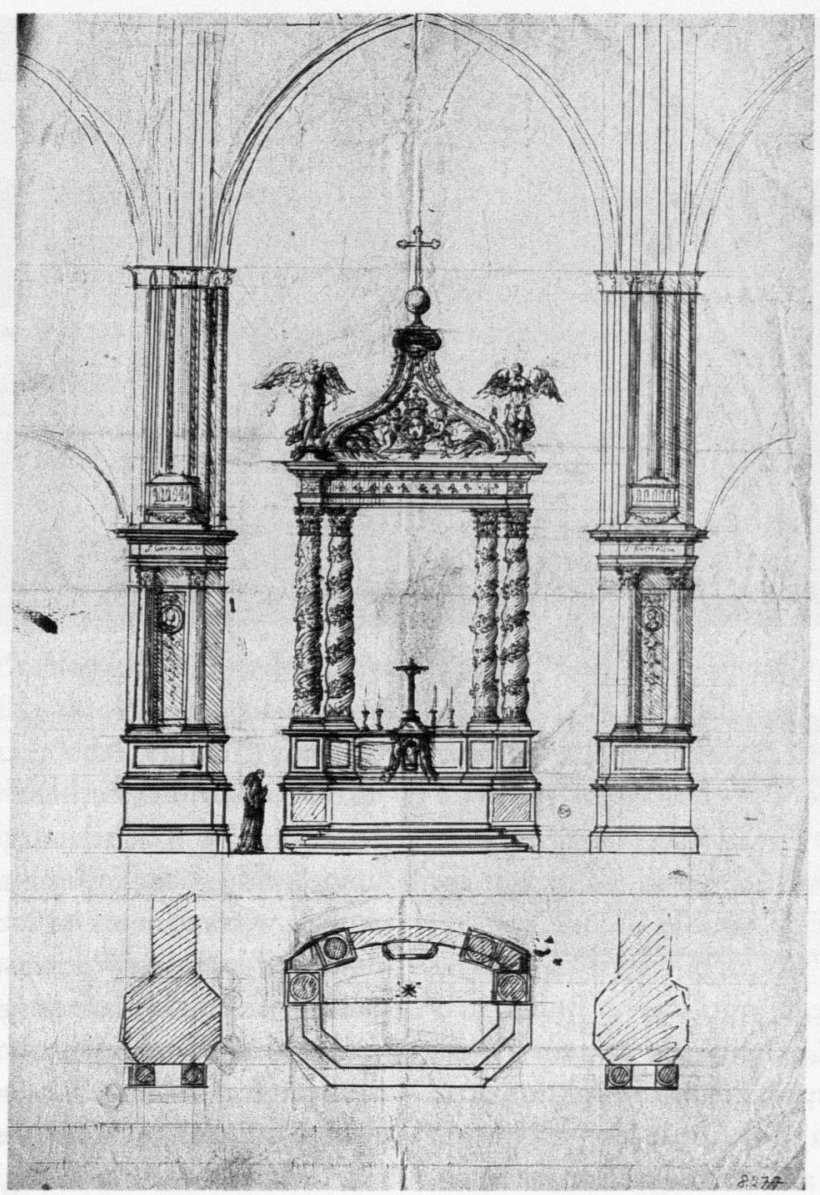

I. Pierre Bullet: Hochaltar für St. Germain-des-Prés, Entwurf (Stockholm, Nationalmuseum)

Planung vorausgegangen, während der sich der zuständige Prior Arnoul de Loo über eine »infinité de contradictions « hinwegzusetzen hatte. De Loo scherte sich nicht um das »eitle Geschwätz « der Leute, wie es in seinem Nachruf heißt, sondern beriet sich mit den "plus habiles gens du metier «?, die ihm zwischen vermutlich 1689 und 1703 Entwürfe vorlegten. Aus den erhalten gebliebenen Zeichnungen erfährt man, wen de Loo für die fähigsten Architekten seiner Zeit hielt: Er befragte wohl zuerst Pierre Bullet, der sich zusammen mit seinem Sohn Jean-Baptiste große Reputation im Bau von Privathäusern erworben und den Margaretenaltar in St. Germain-des-Prés errichtet hatte ${ }^{10}$. Dann wandte er sich an den Surintendant des
Bâtiments und Premier Architecte du Roi Jules Hardouin-Mansart und dessen Mitarbeiter in den Bâtiments ${ }^{\text {I. }}$ Erst als sich Bullets und Mansarts

9 Frère Thierry Ruinart, in: BN, Ms. fr. 18817, f. 236v.

10 Runar Strandberg: Les Projets d'Autel conçus par Pierre Bullet pour St. Germain-des-Prés conservés à Stockholm, Gazette des Beaux Arts VI, 7I, 1968, 33-44; zu Bullets Oeuvre auch: Erik Langenskiöld: Pierre Bullet. The Royal Architect, Stockholm 1959.

"Zeichnungen in BN, Est. Va 269b, fonds de Cotte Nr. 2212-2217, z. T. aufgenommen bei Roger-Armand Weigert: Plans et vues de St. Germain-des-Prés au Cabinet des Estampes de la Bibliothèque Nationale, Mémoires de la fédération des sociétés historiques et archéologiques de Paris et de l'Ile-de-France 9, 1957/58, 105-137; zur Organisation der Bâtiments du Roi vgl. Fiske Kimball: The Creation of the Rococo, Philadelphia 1943, 6off. 


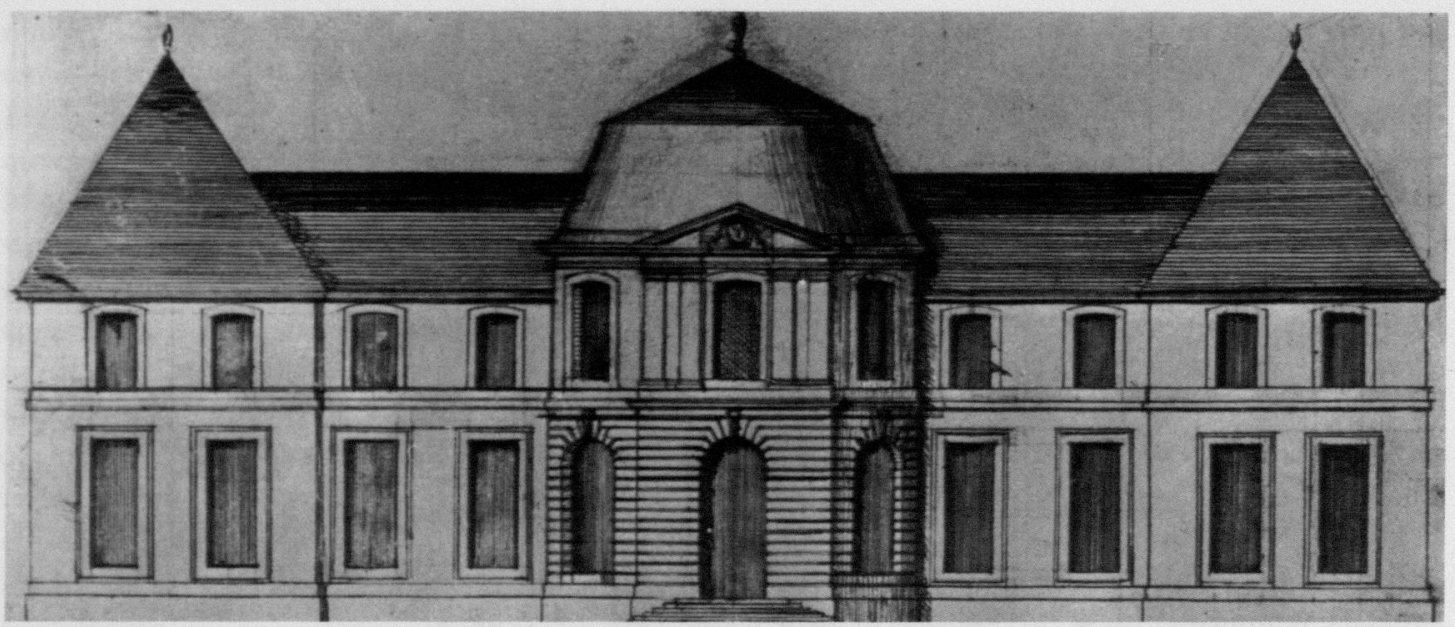

2. Pierre Bullet: Champs-sur-Marne, Entwurf der Gartenfassade (Stockholm, Nationalmuseum)

Projekte als nicht realisierbar erwiesen, erhielt der bisher völlig erfolglose Oppenord den Auftrag ${ }^{12}$.

An den Projekten für St. Germain-des-Prés werden also drei typische Organisationsformen im französischen Baubetrieb um die Wende zum 18 . Jahrhundert sichtbar. Beteiligt waren das kleine unabhängige Baubureau mit Pierre Bullet, das nach Ausweis der Zeichnungen als ein ZweiMann-Betrieb von Vater und Sohn funktionierte; die große und mächtige Behörde der Bâtiments du Roi, in der sich ein arbeitsteiliges Entwurfsverfahren entwickelt hatte und sich die leitenden Architekten zur Ausarbeitung der Pläne immer der Bauzeichner bedienten; und schließlich der Anfänger Oppenord, der über kein Bureau verfügte, sondern alles selbst zeichnete. Unter diesen Voraussetzungen leisten die Projekte für St. Germaindes-Prés Gewähr für einen einigermaßen repräsentativen Überblick über die Möglichkeiten der Architekturzeichnung des ausgehenden Siècle de Louis XIV. Die Zeichnungen liegen in den großen Sammlungen von Stockholm und Paris. Sie stammen also nicht aus dem Archiv des Klosters, sondern waren im Besitz der Architekten verblieben. Es handelt sich daher wohl nicht um die letzten, dem Prior vorgelegten Entwürfe, sondern um Studien, die allerdings sorgfältig ausgeführt sind und dem Stadium von Präsentationsrissen nahe kommen.
Bullets Entwurf (Abb. I) zeigt einen Baldachinaltar zwischen den östlichen Vierungspfeilern der Kirche $^{13}$. Die Zeichnung gibt den Altar und die umgebende gotische Architektur in orthogonalem Aufriß wieder, dem im unteren Viertel des Blatts der Grundriß zugeordnet ist. Eine Skala fehlt. Statt dessen ist ein Mönch dargestellt, der eine ungefähre Vorstellung von den Größenverhältnissen vermittelt. Das Blatt ist über einer Stiftvorzeichnung in Feder und Tusche ausgeführt. Schatten, die die Plastizität der Bauglieder angeben, sind in eiligen, schrägen Parallelschraffuren angelegt. Die Zeichnung konnte so dem Prior von St. Germaindes-Prés nicht präsentiert werden. Die Rippen und Dienste der gotischen Architektur sind unsauber ausgeführt, der Grundriß der Vierungspfeiler ist nur skizziert, die schattierenden Schraffuren sind nicht konsequent angewandt. Dennoch kommt der Entwurf Bullets Vorstellungen von einer Reinzeichnung, mit der man einen Auftraggeber zufriedenstellen konnte, recht nahe. Dies läßt sich an einem Entwurf für die Gartenfassade von Schloß Champs-sur-Marne nachweisen, an dem Bullet etwa zur gleichen Zeit arbeitete

${ }^{12}$ Souchal 1967 (wie Anm. 8), 5orff.; zu Oppenord auch Georges Huard: Oppenord. 1672 à 1742 , in L. Dimier $(\mathrm{Hg}$.$) : Les peintres français au XVIIIe siècle, \mathrm{Bd}$. I, $\mathrm{Pa}$ ris/Brüssel 1928, 3II-329.

${ }_{13}$ Stockholm, Nationalmuseum, CTH 8277; Strandberg 1968 (wie Anm. 10), Abb. I2. 
(Abb. 2) ${ }^{14}$. Die Zeichnung für Champs-sur-Marne ist wieder mit der Feder über einer Skizze mit dem Stift ausgeführt. Parallele Schraffuren, sehr regelmäßig und doch wohl aus der freien Hand, ohne Lineal, gezeichnet ${ }^{15}$, setzen das Dach und die Fenster dunkel gegen die hellen Mauerflächen ab. Sie zeigen die Rundung des Mittelpavillons an und werden durch kurze schräge Strichlagen ergänzt, die die Schlagschatten an den Fenstern und an den Pavillons wiedergeben. Die Schraffuren unterscheiden also die Materialien von Dach und Mauern, spezifizieren sie aber nicht. Ob das Dach mit Schiefer oder Blei gedeckt werden soll oder ob die Mauern aus Naturstein errichtet oder verputzt werden, interessiert den Zeichner nicht. Ausgesprochen unnaturalistisch ist die Wiedergabe der Fenster als gleichmäßig dunkler Flächen. Dennoch wäre wohl niemand der Meinung, hier sei ein unfertiger Bau mit leeren Fensterhöhlen dargestellt, so sehr ist man an die Konventionen der Architekturzeichnung, als die sich das Blatt durch die orthogonale Projektion zu erkennen gibt, gewöhnt. In einem gewissen Widerspruch zur orthogonalen Projektion stehen aber die Schlagschatten. Sie verleihen dem sonst auf einem reinen Liniengefüge beruhenden Aufriß Plastizität; denn sie notieren die Vor- und Rücksprünge, die sonst nur aus einem Grundriß abzulesen wären.

Der Entwurf aus den Bâtiments du Roi (Abb. 3) sieht anders aus ${ }^{16}$. Es ist eine blockartige Mensa abgebildet, die mit einem großen Medaillon dekoriert ist. Auf ihrem "gradin«, den Stufen auf der Rückseite, erheben sich Voluten als Träger für den Schrein des Hl. Germanus aus dem frühen 15. Jahrhundert. Jules Hardouin-Mansart ließ das Blatt von seinem Zeichner und Protégé Pierre Lepautre anfertigen $^{17}$. Lepautre legte zuerst eine sorgfältige, sehr detaillierte Vorzeichnung mit dem Stift an. Dabei benutzte er für die langen geraden Striche an der Mensa und den Stufen ein Lineal. Anschließend gab er mit dem Pinsel einige Details und die Schatten in einer hellgrauen Lavierung an. In einem weiteren Arbeitsschritt zog er die Umrisse in unterschiedlichen Strichstärken aus der freien Hand mit der Feder nach, ließ aber, anders als Bullet, an der beleuchteten linken Seite die Vor-

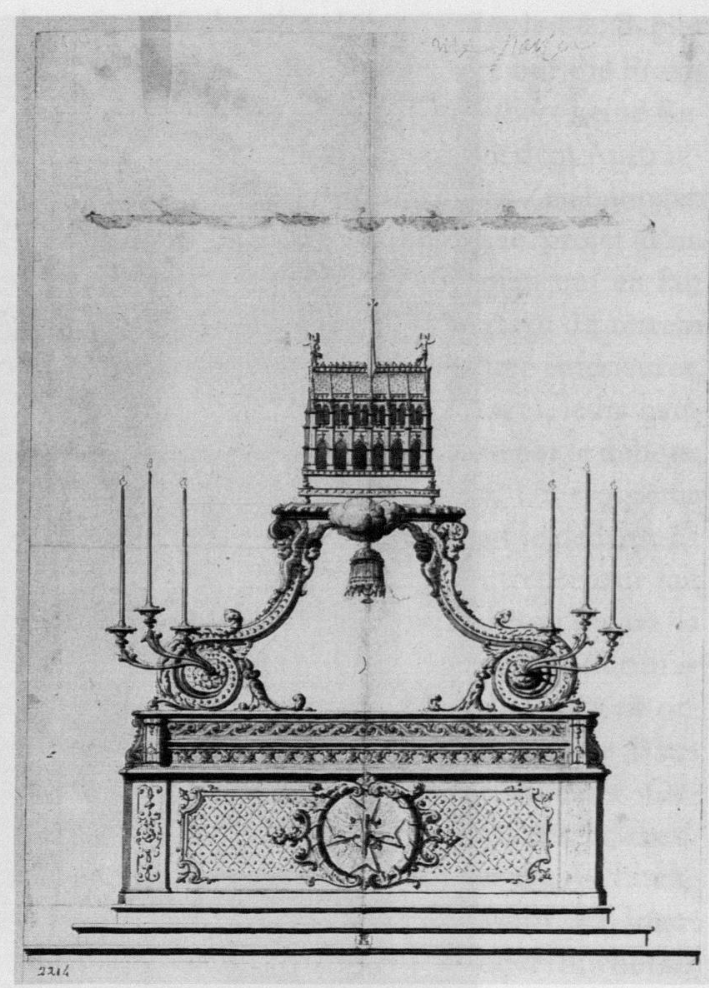

3. Jules Hardouin-Mansart/Pierre Lepautre: Hochaltar für St. Germain-des-Prés, Entwurf (Paris, Bibliothèque nationale)

zeichnung als endgültigen Kontur stehen. Die Zeichnung ist nicht ganz fertiggestellt. Lepautre vergaß, an der rechten Seite der Mensa das Bandelwerkornament mit der Feder nachzuziehen. Die gelbe Aquarellierung, die auf dem zugehörigen

${ }_{14}$ Stockholm, Nationalmuseum, CC 2250 ; R. Strandberg: Le Château de Champs, Gazette des Beaux Arts VI, 6I, 1963, 8Iff., Abb. 9; Bullet ließ Präsentationsrisse häufig von seinem Sohn als lavierte Federzeichnungen noch einmal ins Reine ausführen, z. B. die Projekte für die Porte Royale in la Rochelle, Langenskiöld (wie Anm. Io), Abb. I2If. und weitere Entwürfe für St. Germaindes-Prés, Strandberg 1968 (wie Anm. 10), $36 \mathrm{ff}$.

${ }_{5}$ Zur Schönheit der mit der freien Hand gezogenen Linie in Architekturzeichnungen und Landkarten vgl. L'Art de dessiner proprement les plans, porfils [!], Elevations Geometrales, et Perspectives, soit d'architecture militaire ou civile... Paris ${ }_{1697}$ Préface (nicht paginiert).

${ }_{16}$ BN, Est. Va 269b, fonds de Cotte Nr. 2214.

${ }_{17} \mathrm{Zu}$ Lepautre und der Händescheidung unter den Dessinateurs der Bâtiments: Kimball 1943 (wie Anm. II), 62ff. 


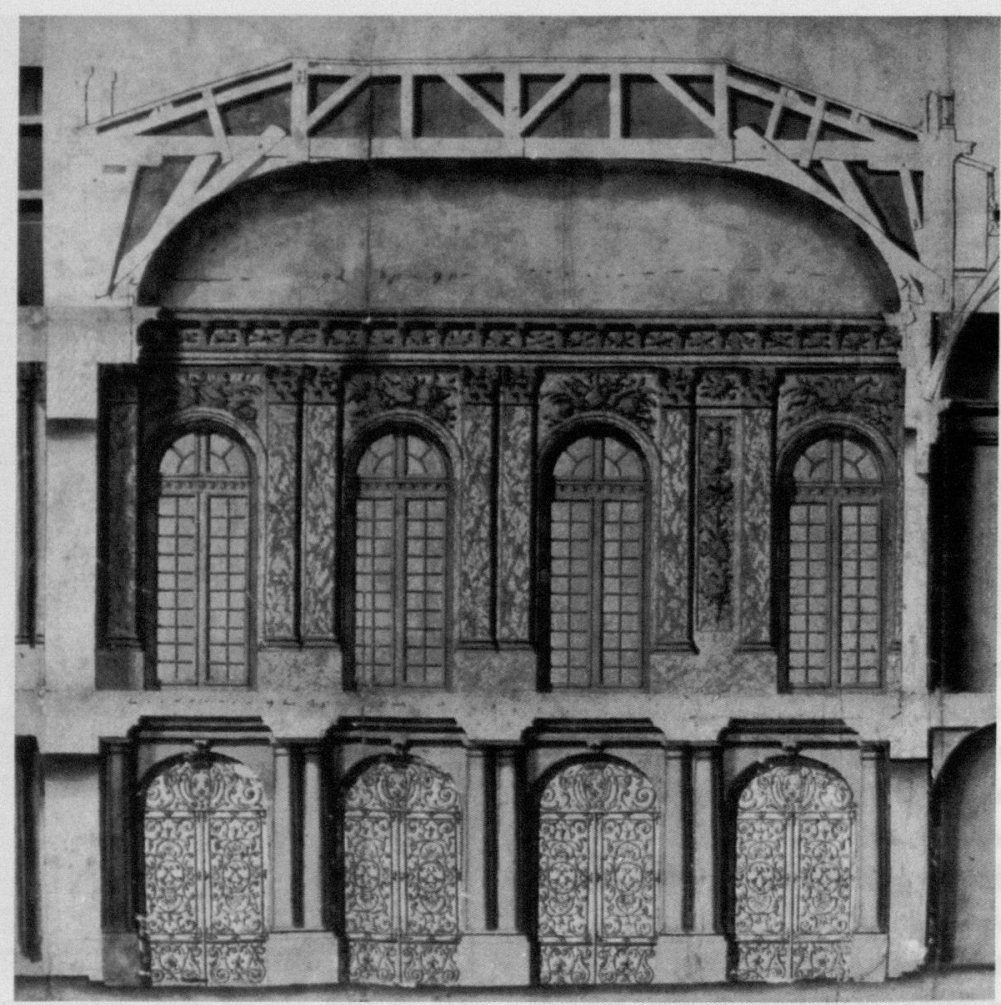

4. Jules Hardouin-Mansart/Pierre Lepautre: Versailles, Salon d'Hercule, Entwurf, Ausschnitt (Paris, Archives nationales)

Schnitt ${ }^{18}$ die geplante Vergoldung des Altars markiert, fehlt hier noch. Zudem trägt das Blatt am oberen Rand die Notiz Hardouin-Mansarts (?): »me parler « - also die Aufforderung, den vorliegenden Entwurf mit ihm zu besprechen.

Ein weiteres Beispiel, jetzt ein fertiges, zur Vorlage vor Ludwig XIV. bestimmtes Blatt, soll die Unterschiede zwischen der Darstellungsweise der Bâtiments du Roi und der Bullets noch deutlicher machen. Vermutlich 1712 zeichnete Pierre Lepautre einen Schnitt durch den künftigen Salon d'Hercule und das darunter liegende Vestibül im Schloß von Versailles (Abb. 4) $)^{\text {ro }}$. Lepautre hat hier auf die Konturierung mit der Feder weitgehend verzichtet. Deutlicher noch als auf seinem Altarentwurf spricht die Stiftvorzeichnung im endgültigen, farbig ausgeführten Zustand mit. Weißen, leeren Grund wie bei Bullet gibt es kaum mehr. Das aufgehende Mauerwerk im Vestibül und in den angrenzenden Räumen ist in hellgrauer Lavierung dargestellt. Die Wandgliederung und die Dekoration des Salons sind bunt aquarelliert. Es sind drei Marmorsorten vorgesehen: weißer geäderter für die Fensterlaibungen, roter für die Sockelzone und grüner für die Pilaster. Die Basen und Kapitelle, die Reliefs mit Musikinstrumenten und der Dekor des Gebälks sind gelb aquarelliert; hier ist die Vergoldung dieser Bronzearbeiten angezeigt. In einem blasseren Gelbton, als ob auf ihnen helles Sonnenlicht stünde, sind die Scheiben der Fenster ausgefüllt. Den Konventionen der Architekturzeichnung folgen die grau angelegten Schatten, die eine Lichtquelle auf der linken Seite voraussetzen, und die Ockertönung der Schnitte durch die Mau-

${ }^{18}$ BN, Est. Va 269b, fonds de Cotte Nr. 2217.

19 $\mathrm{AN}, \mathrm{O}^{1}{ }_{1768} \mathrm{~B}$ 3, I; Projets pour Versailles. Dessins des Archives Nationales, Paris 1985, Nr. 12, 35. 
ern und die Decke. Lepautre erreicht in der Wiedergabe der Proportionen und der Details dieselbe, wenn nicht eine größere Genauigkeit als Bullet. Seine Zeichnungen gewinnen durch die $\mathrm{La}^{-}$ vierung und die Farben aber eine Anschaulichkeit, die Bullets Entwürfen fremd ist.

Die Darstellungsmethode ist also in den Bâtiments du Roi und im Bureau Pierre Bullets identisch. Architekturprojekte werden in orthogonalen Rissen wiedergegeben. Die Zeichentechnik aber ist verschieden. Bullet verfügt über die Schraffur als einzige Möglichkeit, Schatten und die Helligkeitswerte der Baumaterialien anzugeben. In den Bâtiments werden die Schatten in fein abstufender Lavierung in die Zeichnung eingetragen. Die Materialien dagegen sind in ihrer Buntfarbigkeit abgebildet. Farbige Zeichnungen aus den Bâtiments du Roi sind jedoch nicht naturalistisch zu nennen. Die Beleuchtung entspricht der am Bau vorgefundenen Realität nur selten, denn die Lichtquelle wird immer auf der linken Seite angenommen. Die Zeichner führen damit eine Tradition weiter, die schon die Zeitgenossen bemerkten und mit dem »bon goût « erklärten ${ }^{20}$. Die Materialien lassen sich aus den Zeichnungen eindeutig bestimmen. Eine rot-orangefarbene Aquarellierung kann in der Praxis der Bâtiments nur einen einzigen Werkstoff, Marmor aus dem Languedoc, meinen. Eine gelbe Färbung zeigt immer die geplante Vergoldung an. Die größere Leserlichkeit des Entwurfs für den Baubetrieb konnte einen solchen zeichnerischen Aufwand aber kaum rechtfertigen. Ohne daß die Genauigkeit und Eindeutigkeit leiden durften, wurde es zum vordringlichen Anliegen der Zeichner, den Gesamteindruck eines Projekts auf dem Papier anschaulich zu machen.

Die an den Entwürfen Bullets und Lepautres festgestellten Gemeinsamkeiten und Unterschiede lassen die Frage berechtigt erscheinen, ob die französische Architekturtheorie bis in die Zeit um 1700 Regeln für die Zeichnung entwickelt hatte. Bei der Durchsicht der Traktate und der Sitzungsprotokolle der Académie de l'Architecture kommt man rasch zu einem negativen Ergebnis. Fragen der Projektionsmethode und der Zeichentechnik wer- den nur selten berührt. Sébastian Leclerc z. B. gibt 1714 in seinem Traité d'architecture nur die Praxis der Architekten wieder und formuliert keine Regel, wenn er empfiehlt, Bauprojekte dem Auftraggeber in drei orthogonal projizierten Zeichnungen vorzulegen: $\gg$ On fait d'ordinaire le projet d'un Bâtiment par trois Desseins, un plan qui en fait voir l'étendue, la division et le partage du terrein pour les appartemens et commoditez inferieures. Un deuxième qui en montre les étages, leurs hauteurs, et l'apparence que le tout aura par le dehors; et ce Dessein est appelé Elevation. Un troisième nommé Coupe, qui en fait voir tout le dedans: Et c'est sur ces trois Desseins que l'entrepreneur fait son Devis, par lequel il montre jusqu'où ira la dépense, et le temps qui sera necessaire pour finir l'entreprise ${ }^{21}$. Die Vorlage eines Projekts in orthogonalen Rissen, wie sie Bullet und die Bâtiments praktizierten, entsprach also einer Gewohnheit, war aber nicht streng vorgeschrieben. Es gab nur wenige Lehrbücher über die Architekturzeichnung, z. B. die »Art de laver « des Ingenieurs Hubert Gautier von 1687 oder Buchottes »Regles du Dessein et du Lavis tant de l'architecture militaire que civile» von ${ }^{1772}$. Die häufigen Neuauflagen und die Übersetzungen von Gautiers Traktat beweisen, daß durchaus Nachfrage nach solchen Lehrbüchern bestand ${ }^{22}$. Gautier und Buchotte wandten sich vor allem an Ingenieure, $\mathrm{Fe}$ stungsbaumeister und Kartographen. Sie gaben Anweisungen über Kürzel und die Farbverteilung nur für den militärischen Bereich, da hier jeder Irrtum ausgeschlossen werden müsse, während man in der Zivilbaukunst dem eigenen »goût « fol-

${ }^{20}$ Buchotte: Regles du Dessein et du Lavis tant de l'Architecture militaire que civile, Paris $1722,39$.

${ }^{2 \pi}$ Sébastien Leclerc: Traité d'architecture avec des remarques et des observations trés-utiles pour les Jeunes Gens, qui veulent s'appliquer à ce bel art, Paris 1714, 3 .

${ }^{22}$ Hubert Gautier: L'Art de laver ou nouvelle manière de peindre sur papier suivant le Coloris des Dessins qu'on envoye à la Cour, Lyon 1687. Die zweite französische Ausgabe erschien 1708 , deutsche Übersetzungen kamen 175I und 1764 , eine italienische 1760 heraus. Buchottes Traktat wurde 1743 , 1754 (zweimal) und 1755 neu aufgelegt. Außerdem ist zu nennen: Courtonne: Traité de la perspective pratique avec des remarques sur l'architecture..., Paris 1725 . 
gen dürfe ${ }^{23}$. Für die Architekten selbst war der Abstand von der Theorie des Dessin als dem nobilitierenden Ursprung der Künste, also auch der Architektur, zur Praxis des Zeichnens zu groß, als daß sie sich für die Aufstellung eines Regelwerks hätten interessieren können ${ }^{24}$.

Sie begnügten sich daher mit den kurzen Äußerungen zweier Autoritäten: Vitruv und Alberti. Vitruv fordert in der Planung drei Zeichnungen: den Grundriß, den orthogonal projizierten Aufriß und die perspektivische Ansicht, die er Ichnographia, Orthographia und Scenographia nennt ${ }^{25}$. Alberti grenzt die Zeichnung des Architekten durch ihre größere Rationalität von der des Malers ab. Der Architekt brauche in der Zeichnung keine Schatten und keine Perspektive, da das Relief des Baus im Grundriß korrekt wiedergegeben werde. In den unterschiedlichen Auffassungen Vitruvs und Albertis ist der Zwiespalt angelegt, der die Architekturzeichnung in Frankreich bestimmen wird. Alberti setzt sich für eine Methode ein, die auf der Wissenschaft von der Geometrie beruht und demnach die Maßverhältnisse eines Baus eindeutig darstellt ${ }^{26}$. Er fordert damit eine Zeichnung, die von der Realität des (künftigen) Baus stärker abstrahiert, als es die perspektivische Ansicht oder gar die Vedute vermögen. Vitruv dagegen läßt das Schaubild zu²7. Beide Autoren äußern sich nicht über die graphischen Techniken. Indes scheint Alberti in seinem Beharren auf dem $\mathrm{Li}^{-}$ niengefüge und der Ablehnung der Schatten den Pinsel für die Wiedergabe von Architektur auszuschließen.

Die französischen Architekten des 16. Jahrhunderts verwendeten für Projektzeichnungen in vielen Fällen die Feder. Die Begründung für diese Praxis des Entwerfens gibt Philibert de L'Orme, der Albertis "De architectura " kannte, in seinem Traktat von 1567. De L'Orme bemüht sich, in den einleitenden Kapiteln des Buchs den Beruf des Architekten zu definieren und gegen mögliche Konkurrenten zu verteidigen. Dabei sieht er die größtmögliche Sorgfalt in allen Stadien der Planung als wichtige Aufgabe und vordringliche Pflicht, die den qualifizierten und gelehrten Architekten über den reinen Praktiker, den Maître-Ma- çon, erhebt. Aus der Praxis dagegen kommt seine Forderung nach dem korrekten, d. h. orthogonalen Entwurf, mit der er sich gegen andere gefährliche Konkurrenten, die Maler, wehrt. De L'Orme ärgert sich besonders über die Komplizenschaft von Bauunternehmern und Malern, die beide vom Planen nichts verstünden, aber häufig in diesem Bereich zusammenarbeiteten: »Tous les jours se voyent plusieurs donneurs de portraicts et faiseurs de desseins, dont la pluspart n'en sçauroient bien trasser ou descrire aucun, si ce n'est par l'ayde et moyen des peintres, qui les sçavent plustost bien farder, laver, ombrager, et colorer, que bien faire et ordonner avecque toutes leurs mesures. Ie dy asseurément que tous Architectes et maistre $\mathrm{Ma}$ çons faisants ainsi, sont comme perroquets; car ils sçavent bien parler, mais ils ne cognoissent ce qu'ils disent, ny moins la fin de ce qu'ils promettent, qui est de bien faire... Bref ils patelinent si bien que leursdits tant beaux portraicts et desseins,

${ }_{23}$ Art de dessiner 1697 (wie Anm. I5), Préface (nicht paginiert); Buchotte 1722 (wie Anm. 20), Préface (nicht paginiert); vgl. auch Georg Germann: Der farbige Architektur-Entwurf, in Festschrift A. Knoepfli, Zürich 1980, 188.

${ }^{24}$ Dessin ist kein Lehrgegenstand in François Blondel: Cours d'architecture enseigné dans l'Académie royale d'architecture, Paris 1698; über den Mangel an praktischen Regeln klagt Paul Fréart de Chantelou: Journal de Voyage du Cavalier Bernin en France, Aix-en-Provence 1981,183 (13. 9. I665): »on dit assez les règles de l'art, mais rarement ou jamais celles de l'ouvrierk.

25 Vitruvii de architectura libri decem I, 2 (Ausgabe Darmstadt $1964,36 \mathrm{ff}$.).

${ }^{26}$ Leon Battista Alberti: L'Architettura (De re aedificatoria), hg. v. g. Orlandi, Mailand 1966, Buch II, I, 99; vgl. Wolfgang Lotz: Das Raumbild in der italienischen Architekturzeichnung, Mitteilungen des kunsthistorischen Instituts in Florenz 1956, 213-226.

27 [Claude Perrault]: Les dix livres d'architecture de $\mathrm{Vi-}$ truve corrigez et traduits nouvellement en François avec des Notes et des Figures, Paris, ${ }^{2} 1684$, Io, note 7 . Perrault weist in dieser $\mathrm{Fu}$ Bnote den Kommentar Daniele Barbaros zurück, der Scenographie nach philologischen Korrekturen als Sciographie aufgelöst hatte. Barbaro kam aufgrund des lateinischen Wortlauts - scaeno/sciographie est... adumbratio - zu dem Schluß, bei dieser Art Zeichnung müsse es sich um einen lavierten (schattierten) Schnitt handeln. Damit schied er, wie Alberti, die perspektivische Ansicht aus dem Kanon der Architekturzeichnungen aus (D. Barbaro: M. Vitruvii Pollionis de Architectura libri decem cum commentariis, Venedig ${ }^{2}$ I567, i8f.). 


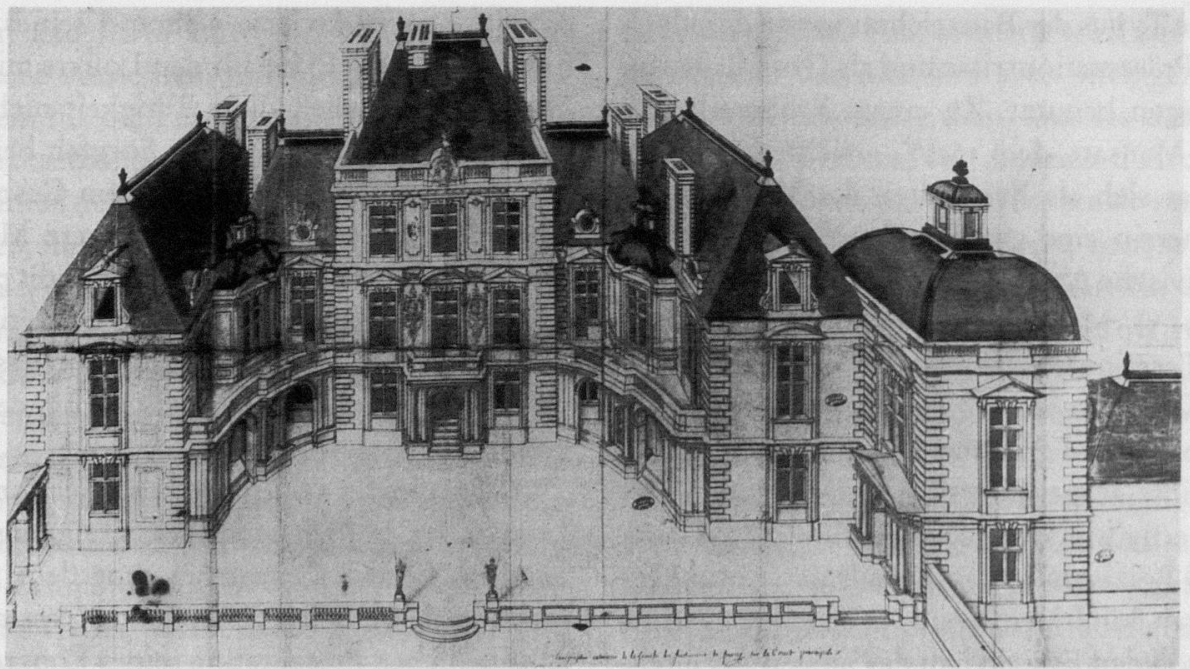

5. François Mansart: Berny, Entwurf (Paris, Archives nationales)

servent de filets à prendre ceux qui sont trop credules et eschauffez de faire bastir sans y rien cognoistre $\ll^{28}$.

Am Schluß wird klar, welche Aufgabe, die Vitruv und Alberti vornehm verschweigen, der Architekturzeichnung u. a. zukam. Mit dem Entwurf warb der Architekt um den Auftrag; und de L'Orme hatte wohl nur zu gut erfahren, daß dies mit einer kolorierten, perspektivischen Ansicht leichter fiel als mit einem orthogonalen, korrekt proportionierten, in Feder ausgeführten Riß, dessen größerer Abstraktionsgrad die Lektüre durch den in der Baukunst unerfahrenen Auftraggeber erschwerte. Angesichts dieser Konkurrenzsituation im Bauwesen ist es erstaunlich, daß sich der orthogonale Riß in Federzeichnung zunächst durchsetzte und sich als ein möglicher Standard des Präsentationsentwurfs mit Pierre Bullet bis in das frühe 18 . Jahrhundert hielt. Dies erklärt sich vielleicht aus dem Selbstbewußtsein der Architekten, die in der geometrisch korrekt abbildenden Zeichnung ihr wichtigstes Mittel zur Darstellung von Architektur sahen. Zudem bewährte sich diese Art des Zeichnens in der Baupraxis. Besonders wenn die Projektierung und die Ausführung nicht in einer Hand lagen, d. h. die Architekten das Bauen selbst den Maîtres-Maçons überließen, war Exaktheit und Eindeutigkeit der Pläne angebracht ${ }^{29}$. Neben der Federzeichnung blieb das "Schattieren, Lavieren und Kolorieren ", das de L'Orme so vehement ablehnte, bei den Architekten durchaus in Gebrauch. Beispiele finden sich zunächst vor allem in Aufnahmen bestehender Bauten, moderner und antiker, oder in Idealentwürfen. Es kennzeichnet das Verhältnis der Architekten zu ihrem Publikum, daß die Technik der Lavierung oder bunten Aquarellierung im I6. und 17. Jahrhundert meistens auf perspektivische Ansichten angewandt wurde, die von vornherein größere Anschaulichkeit zu garantieren schienen. Ein charakteristischer Fall ist Jacques Androuet du Cerceau, der seine Aufnahmen nach antiken Bauten und seine Projekte für Werbezwecke auf Pergamentblättern in sorgsam lavierten Ansichten zusammenstellte ${ }^{30}$.

${ }^{28}$ Philibert de L'Orme: Le premier tome d'architecture (I562), Rouen 1648, 2If. (Kap. Io).

29 Vgl. J. M. Savignat: Dessin et architecture du moyen âge au XVIIe siècle, Paris ${ }^{2} 1983$, I36ff.

${ }^{30}$ Heinrich Geymüller: Les Du Cerceau, leur vie et leur œuvre. D'après de nouvelles recherches, Paris 1887, Iosff. Eine Liste der Sammelbände mit Zeichnungen Du Cerceaus enthält Rosalys Coope: Salomon de Brosse and the Development of the Classical Style in French Archi- 
Derselbe Typus der Bauzeichnung wurde jedoch auch für Präsentationsrisse und als Grundlage von Bauverträgen benutzt. $\mathrm{Zu}$ einem Frühwerk von François Mansart, dem $1622 / 24$ errichteten Schloß Berny, hat sich als Bestandteil des Vertrags mit der Bauherrin eine großformatige $(69 \times 121 \mathrm{~cm})$ perspektivische Ansicht aus der Vogelschau erhalten (Abb. 5). Mansart hat seinen Entwurf nach Vitruvs Terminologie korrekt als "Scenographie" betitelt. Das Blatt ist sorgfältig laviert, die Dächer des Schlosses sind graublau aquarelliert, Zierat ist in Goldtinte ausgeführt ${ }^{35}$. Diese Darstellung von Schloß Berny war sehr geeignet, durch ihre Plastizität und Präzision in den Details der Auftraggeberin ihren künftigen Besitz präsent zu machen und sie von den Fähigkeiten des jungen Architekten zu überzeugen.

François Mansart zog in späteren Jahren den orthogonal projizierten Riß in Federzeichnung vor ${ }^{32}$. In den Bâtiments du Roi setzte sich während der Amtszeit Louis Le Vaus als Premier Architecte und mit Beginn der großen Bauunternehmungen Ludwigs XIV. im Gegensatz zu den Bureaus unabhängiger Architekten die lavierte farbige Zeichnung als Standard des Präsentationsrisses durch. Le Vau hatte sich von 1659 an bemüht, in den sorgfältig lavierten Rissen zum Collège des Quatre Nations den Erwartungen Mazarins und Ludwigs XIV. zu genügen, der sich zu einem kundigen, darum aber nicht minder anspruchsvollen Bauherrn entwickeln sollte33. An den Projekten für den Ostflügel des Louvre aus den sechziger Jahren des 17. Jahrhunderts ist der neue Standard der Architekturzeichnung bereits deutlich erkennbar. François Mansart beteiligte sich an der Konkurrenz noch mit Federzeichnungen ${ }^{34}$. Alle anderen Architekten - soweit das fragmentarisch erhaltene Material eine solche Feststellung erlaubt - reichten lavierte oder kolorierte Entwürfe ein ${ }^{35}$. Durch die Konkurrenz der Italiener, deren Projekte 1664 in Paris eintrafen ${ }^{36}$, verstärkte sich der Erwartungsdruck auf die Franzosen. Gerade die italienischen Architekten schätzten die Zeichnung als Möglichkeit zur Präsentation ihrer Fähigkeiten sehr hoch ein. Dies galt auch, wenn der Architekt die Chance zum direkten Kontakt mit seinem Auftraggeber erhielt. Bernini lavierte während seines Aufenthalts in Paris die Pläne für den Louvre mit eigener Hand und überließ diese Tätigkeit nicht seinen mitreisenden Gehilfen. Seine Sorgfalt beim Reinzeichnen der Pläne geht aus einem Gespräch mit Chantelou hervor, der ihm mehrere Male beim Lavieren zuschaute: »Il (Bernini) m'a dit par diverses fois qu'il falloit bien de la discrétion à cet ouvrage dans l'épargne des lumières et des ombres; qu'il ésperait que le Roi trouveroit cela à son gré«37.

Was Bernini für scine lavierten Zeichnungen zum Louvre so höflich und vorsichtig ausdrückte, empfahl Daniel Cronström r7os dem schwedischen Hofarchitekten Nikodemus Tessin, der zur anschaulichen Präsentation seines Louvreprojekts sogar ein Modell anfertigen ließ, mit unverblümter Deutlichkeit: »Comme il fault plaire aux femme de la cour et à tout le peuple ignorant des courtisans, je crois que pour les mieux charmer il faudroit laver le tout [das Modell] d'une teinte couleur de pierre et dorer certains ornements comme basreliefs, ballustrades, etc. ${ }^{38}$.

tecture from 1565 to 1630 , London 1977, I93f.; vgl. außerdem ein Album in Privatbesitz (Arnold Nesselrath: I libri di disegni di antichità. Tentativo di una tipologia, in: Memoria dell'antico nell'arte italiana, Turin 1986 , Bd. 3, 140).

3r Allan Braham/Peter Smith: François Mansart, London 1973, Bd.1, 192f., Bd. 2, Abb. 65.

${ }_{32} \mathrm{Zu}$ Mansarts Zeichnungen vgl. die Episode in Charles Perrault: Les Hommes illustres, qui ont paru en France pendant ce siècle, Paris 1696-1700, Bd. 1, 16rf.

33 Abbildungen der Entwürfe in: La Chapelle du Collège des Quatre Nations (1662-1967), Monuments historiques 9,1963 .

34 Braham/Smith 1973 (wie Anm. 31), Bd. I, I22ff., Bd. 2, Abb. $470-539$.

35 Louis Hautecour: L'Histoire des Châteaux du Louvre et des Tuileries, Paris 1927, I43ff., JeanClaude Daufresne: Louvre et Tuileries, Architectures de papier, Brüssel 1987, $57 \mathrm{ff}$., mit weiterer Literatur.

${ }^{6}$ Die vollständigste Übersicht über die "italienischen" Projekte enthält: Karl Noehles: Die Louvre-Projekte von Pietro da Cortona und Carlo Rainaldi, Zeitschrift für Kunstgeschichte 24, 196I, 40-74.

37 Chantelou I981 (wie Anm. 24), 56 (10. 7. 1665); ähnlich 47 (1. 7. 1665).

${ }_{38}$ Les Relations artistiques entre la France et la Suède 1693-1718. Nicodème Tessin le jeune et Daniel Conström. Correspondance, Stockholm 1964, 34 I (19.6.1705). 
Schatten und Farbe im orthogonalen Riß, perspektivische Ansichten und Modelle waren aber nicht allein für die Präsentation des Projekts vor einem fachunkundigen Publikum wichtig, sondern konnten den Architekten selbst die Gelegenheit bieten, ihr Projekt besser zu beurteilen. Nach Perraults Vitruvkommentar von 1684 diente die "Scenographie« dazu, den "effet de l'execution parfaite de tout l'Edifice« wiederzugeben ${ }^{39}$. Das Modell sei allerdings noch anschaulicher. 40 Jahre später wertete Courtonne die Zeichnung auf: Modelle seien immer kleiner als die projektieren $\mathrm{Ge}$ bäude, die korrekte perspektivische Zeichnung dagegen nehme einen bestimmten Betrachterstandpunkt an und könne daher den Bau und seine Teile darstellen, »qu'on ne sçauroit guère juger de leur effet par une simple élevation geometrale«4․ Die Aufgabe der Schatten beschreibt Buchotte 1722: Sie heben die Teile voneinander $a b$, »afin de representer les objets qu'ils nous paroissent d'après nature; ce qui est un effet optique «4i. Der optische Effekt in der Darstellung der Projekte und die am Bau angestrebte Wirkung korrespondieren in diesen Aussagen. Zentralperspektive und Schatten dienen dem Architekten dazu, sich im Medium der Zeichnung einen Bau von einem angenommenen Betrachterstandpunkt zu vergegenwärtigen oder die Gliederung der Fassade mit ihrer Verteilung von Licht und Schatten zu studieren. Zeichnungen konnten also eine wichtige Funktion in der Planung von Gebäuden übernehmen, die, wie die Diskussionen um die Kolossalordnung und ihre Anwendung am Louvre belegen, auf ihren $»$ effet $\ll$ hin konzipiert wurden ${ }^{2}$. Schattierte Risse waren daher nur um eine annähernde, nicht eine exakt ablesbare Wiedergabe des Fassadenreliefs bemüht. Buchotte z. B. beschränkt sich in seinem Lehrbuch auf ganz allgemein gehaltene Ratschläge für die Anlage der Schatten, da eine $\gg$ Theorie« ein ganzes Buch nötig mache43. Jacques-François Blondel wird in seinem $»$ Cours d'architecture « $177 \mathrm{x}$ eine wissenschaftlich begründete Lehre der Schatten fordern, diesen Anspruch aber selbst weder im Text des Cours noch in den mitgelieferten Rissen einlösen. Die Schattierung ist für ihn nicht mehr bloßer Zusatz zum korrekt aufgenommenen Riß, sondern wird zur "manière de dessiner l'architecture avec intelligence. Pour cela il faut descendre dans tous les détails de la théorie des ombres; les desseins d'Architecture étant pour l'Architecte une espèce de modèle, qui lui fait juger si l'idée qu'il en a conçue lui offre celle qu'il en avoit droit d'espérer. En effet cette théorie lui apprendra à concevoir ce qu'il est necessaire d'ajouter ou de retrancher dans les différentes parties de son projet, pour parvenir à un plus grand succès «44.

Die Abkehr von der Federzeichnung, die um I700 nur der in diesem Punkt altmodische Bullet beibehielt, erfolgte also in Reaktion auf die Ansprüche der Bauherrn und die Anforderungen, die die Architekten an die Zeichnung im Planungsprozeß richteten. Diese Entwicklung der Zeichentechnik sollte für das Berufsbild der Architekten Folgen haben. Denn als die Tätigkeit der Bâtiments du Roi im letzten Viertel des I7. Jahrhunderts bisher nie erreichte Ausmaße annahm, war das hohe Niveau der Bauzeichnung nur noch durch Arbeitsteilung zu retten. Schon Louis Le Vau hatte für die Anfertigung der Reinzeichnungen untergeordnete Architekten, vor allem François d'Orbay, der ihm im Amt des Premier Architecte nachfolgen sollte, herangezogen45. Der größte Systematiker an der Spitze der Bâtiments wurde 1699 Jules Hardouin-Mansart ${ }^{46}$. Während seiner Amtszeit etablierte sich endgültig der Beruf des Dessinateurs, des Zeichners, der im Gegensatz zu den Architekten die Praxis des Bauens nicht

39 Perrault $x 684$ (wie Anm. 27), ro, note 7.

40 Courtonne 1725 (wie Anm. 22), 89.

41 Buchotte 1722 (wie Anm. 20), 34 f.

${ }^{22}$ Vgl. z. B. den Advis de M. le Vau le jeune [= François

Le Vau] sur le nouveau dessin du Louvre, in: Albert Laprade: François d'Orbay. Architecte de Louis XIV, Paris 1960, 342ff. (Nr. 6/7).

43 Buchotte 1722 (wie Anm. 20), 4 Iff.

${ }_{44}$ Blondel r77r (wie Anm. 6), Bd. 3, XXXIII. Die geometrisch korrekte Angabe der Schatten unter einem einheitlichen Winkel von $45^{\circ}$ wurde erst im 19. Jahrhundert verbindlich. Savignat 1983 (wie Anm. 29), I56; anders Dagobert Frey, s.v. Architekturzeichnung, Reallexikon zur Deutschen Kunstgeschichte, Bd. I, 1937, Sp. Ioogff. 45 Laprade 1960 (wie Anm. 42), infff.

${ }^{46}$ Kimball 1943 (wie Anm. II), 6 off. 
kennengelernt hatte, sondern aus anderen Sparten des Kunstbetriebs kam. Pierre Lepautre z. B., der die Entwürfe für St. Germain-des-Prés zeichnere, war als Kupferstecher tätig gewesen, bevor Hardouin-Mansart ihn in die Bâtiments holte.

Die Dessinateurs hätten Le Bruns Gleichsetzung von Zeichnung und Architektur sicher zugestimmt. In der schönen Zeichnung lag für sie die eigentliche Leistung des Architekten, aus der sie sich das Recht nahmen, sich selbst als "Architecte ordinaire du Roi« zu betiteln ${ }^{47}$. Von den Architekten aber wurden sie in ihre Schranken verwiesen und daher offiziell immer nur $»$ Dessinateur " genannt. Die Konkurrenzsituation, in der sich Philibert de l'Orme im i6. Jahrhundert zu den Malern befunden hatte, kehrte jetzt wieder, da sich die Dessinateurs mit ihrer minimalen praktischen Erfahrung als Baumeister versuchten und damit den Architekten nicht nur Aufträge entzogen, sondern durch häufige Fehlschläge dem Prestige des Berufs schadeten. Explizit sagt es 1725 Courtonne: "Il ne suffit pas d'avoir exercé la fonction de Dessinateur pendant quelques années pour en [de l'architecte] mériter le Titre, comme cela n'est que trop ordinaire. Car bien loin d'avoir acquis la plus grande partie des Sciences qui sont absolument nécessaire, on prend cette qualité sans avoir même la Pratique ny cette experience consommé dans les Bâtimens, et qui ne s'apprend point dans le Cabinet, mais par des travaux pénibles et non interrompus $\ll^{48}$.

47 Pierre Lepautre ließ z. B. folgende Annonce verbreiten: "Le Pautre. Architecte et Graveur ordinaire du Roi, Montre a Dessigner l'Architecture, la Figure, l'Ornement, le Paisage etc. ...«(BN, Est, Ed. 43).

$4^{8}$ Courtonne 1725 (wie Anm. 22), 107.

49 Pierre Mariette: Abecedario... et autres notes inédites... hg. v. Ph. de Chennevières/A. de Montaiglon, Paris I851I860, Bd. 2, 276, zu Jacques Gabriel: "...étoit expert dans la conduite du bâtiment, mais il n'auroit pas pu dessiner le moindre bout d'ornement. Est-ce là être architecte? « Louis de Rouvroy, duc de Saint-Simon. Mémoires, hg. v. A. de Boislisle, Paris 1879-1928, Bd. 16, 37ff., zu Jules Hardouin-Mansart und Robert de Cotte: "Il étoit ignorant dans son métier, de Coste son beau frère, qu'il fit premier architecte, n'en savoit pas plus que lui. Ils tiroient leurs plans, leurs desseins, leurs lumières, d'un dessinateur des bâtiments nommé l'Assurance qu'ils tenoient tant qu'ils pouvoient sous clef...* Das Gegenteil schreibt ein unbekannter Schüler Hardouin-Mansarts: "ll ne s'est pas seulement contenté de donner des des-
An der Architekturzeichnung schieden sich die Parteien. Die Sicht des Publikums und die Sicht der Architekten begannen wieder zu differieren. Um die Mitte des r8. Jahrhunderts häufen sich die Kommentare, die den berühmten Architekten des 17. Jahrhunderts die Qualifikation für ihren Beruf absprechen, weil sie nicht hätten zeichnen können. Aus dem Fehlen eigenhändiger, repräsentativer Risse wird der Schluß gezogen, alle entwerferische Arbeit, besonders im Bereich der Innendekoration, sei nicht von den Architekten selbst, sondern von den von ihnen unterdrückten Dessinateurs vollbracht worden 49 .

Die Bedeutung der mornements qui enrichissent les bâtiments« als architektonische Aufgabe hatte Le Brun 1672 zum Anlaß genommen, Maler und Bildhauer als universale Künstler zu Übergriffen auf das Arbeitsgebiet der Architekten zu verleiten ${ }^{50}$. Die veränderte Situation im Bauwesen des frühen 18. Jahrhunderts gab ihm im Nachhinein recht: Das im Verhältnis zur Zeit um 1670 deutlich geringere Bauvolumen ${ }^{x}$ und die daraus resultierende Konzentration der Tätigkeit auf profane wie sakrale Innenausbauten, die detaillierte Vorlagen für die ausführenden Handwerker nötig machten, konnten nun die Entstehung neuer Darstellungsweisen für die Entwürfe fördern 52 . Die Architekten selbst hatten diese Entwicklung zur aufwendigen, farbigen und sorgfältig lavierten Zeichnung jedoch längst in Gang gesetzt, als sie auf die An-

seins pour les bastimens et distributions des dedans mais encore pour tous les ornemens en general qui en dependent et jusques au moindres profils...\& (zitiert nach Braham/Smith 1973 (wie Anm. 31) Bd. I, I63) Kimball 1943 (wie Anm. II) und in einer sehr undifferenzierten Weise auch Laprade 1960 (wie Anm. 42) setzen also eine Tradition des 18 . Jahrhunderts fort, wenn sie den Premiers Architectes der Bâtiments du Roi jede zeichnerische Entwurfstätigkeit abschreiben.

so Wie Anm. I.

s Einen Maßstab geben die jährlichen Gesamtausgaben der Bâtiments du Roi: Etat abrégé des recettes et dépenses (1662-1770) (An, KK 355), z. T. publiziert in J. J. Guiffrey: Comptes des Bâtiments du Roi, Paris 188ı, Bd. I, XVff. Die Verhältnisse innerhalb der Bâtiments lassen sich indes nur mit Einschränkungen auf den Privatsektor übertragen.

52 Vgl. Quatremère de Quincy I80r (wie Anm. 6), 209; Guillerme 1982 (wie Anm. 7), 4of. 
sprüche und den architektonischen Unverstand ihrer Auftraggeber reagierten.

Der dritte Teilnehmer an der Konkurrenz um den Auftrag für St. Germain-des-Prés, Gilles-Marie Oppenord, vereinigte die Tätigkeiten eines Architekten und Dessinateurs in einer Person. An seinen Zeichnungen läßt sich prüfen, welche Möglichkeiten die liberale Haltung der Zeitgenossen in Fragen der Darstellungsmethode und -technik von Bauprojekten bot, wenn sich die Tendenz zum anschaulichen, präsentablen Riß mit der gezielten Förderung der zeichnerischen Fähigkeiten eines Baumeisters verband. Oppenords Ausbildung zum zeichnenden Architekten, die an der französischen Akademie in Rom erfolgte, ist durch die Korrespondenz des Direktors La Teulière mit dem Surintendanten in Paris, de Villacerf, in allen Einzelheiten überliefert. Wie kaum ein anderes Dokument verdeutlicht diese Korrespondenz die Erwartungen, die der Leiter der königlichen Baubehörde, selbst kein Architekt, sondern den Dilettanten zuzurechnen, gegen Ende des 17. Jahrhunderts an die Zeichenkünste seines Personals richtete.

Oppenord kam 1692 als Protégé Villacerfs nach Rom, ohne zuvor eine herkömmliche, praktische Ausbildung zum Architekten erfahren zu habens3. Das akademische Unterrichtsprogramm für einen angehenden Architekten war ungewöhnlich, denn bisher waren vorwiegend Maler und Bildhauer und nur wenige Architekten zur Ausbildung an die Akademie in Rom gekommen ${ }^{54}$. Die Maßnahme des Surintendanten erklärt sich vielleicht aus dem gestiegenen Bedarf an vielseitig verwendbaren Kräften und fähigen Zeichnern innerhalb der Bâtiments du Roi. Es bestand indes kein Zweifel, daß Oppenord als Architekt, nicht nur als Zeichner, eingesetzt werden sollte. $\mathrm{Zu}$ seiner Erziehung zum umfassend gebildeten Baumeister gehörte außer Übungen in der Orthographie und im Schönschreibenss vor allem das Zeichnen. Villacerf ließ Oppenord dieselbe Ausbildung zuteil werden wie den Malern und Bildhauern. Oppenord wurde deshalb zum Zeichnen nach dem Modell zugelassen ${ }^{6}{ }^{6}$ und immer wieder dazu gedrängt, über dem Aufnehmen antiker und moderner Bau- ten das Studium der menschlichen Figur nicht zu vernachlässigen. $1695 \mathrm{z}$. B. schrieb Villacerf an $\mathrm{La}$ Teulière: "Je vous prie d'avoir soin que le Sr. Oppenord dessine bien la figure et qu'il s'y aplique sérieusement, parce que, quand il songe à être Architecte cela lui sera fort avantageux; il ne faut pas qu'il se contente de la croquer sur ses plans ni de la dessiner en petit, comme font la plupart des dessinateurs «s7. Eine Nebenaufgabe der sorgfältig ausgeführten, nicht im Stadium der Federskizze belassenen Architekturaufnahmen Oppenords benennt ein Brief $\mathrm{La}$ Teulières an den Surintendanten von 1696: »[Oppenord] dessine les plans et les élévations des plus beaux édifices modernes qui soient à Rome, des Eglises surtout, ce qui certainement vous donnera du plaisir à voir, et je ne doute pas même que le Roy, qui a le discernement si bon en toutes choses, ne peût se divertir quelques momens à voir tous ses desseins, car le Sr Openhort a soing de les laver et de les bien esclairer pour donner à toutes les parties le relief qu'elles ont et la couleur, avec tous les ornemens dessinés de bon goust ¿ $^{8}$. Villacerf hatte sich den Nutzen, den die Bâtiments aus Oppenords siebenjähriger Lehrzeit in Italien, seinen Skizzenbüchern und

53 Antoine-Nicolas Dézallier d'Argenville: Vies des fameux architects depuis la Renaissance des Arts, Paris 1787, 434; Huard 1928 (wie Anm. 12), 31 Iff.

54 Bis zur Einführung des Rompreises für Architektur (1720) waren nur sechs Architekten an der Akademie in Rom gewesen: Daviler und Desgodets (1676/77), Bruand (1683), Oppenord und Cartaud (1692) und Antonie (1699); vgl. Procès-verbaux de l'Académie royale d'architecture I671-1793, Paris ignff., Bd. 4, XVI; F. Célard/A. Thiry/E. Pérouse de Montclos: Les Prix de Rome, Paris 1984.

ss Correspondance des directeurs de l'Académie de France à Rome avec les surintendants des Bâtiments, Paris r887ff., hg. v. A. de Montaiglon/J. J. Guiffrey, Bd. 2, 170 (6. II. 1695), Villacerf an La Teulière: "Je voudrois savoir aussi s'il écrit bien et s'il sçait bien l'orthographe parce qu'ordinairement les gens de son mèrier écrivent mal." Letzteres bezieht sich vielleicht auf den Premier Architecte Hardouin-Mansart, über den Cronström 1699 schreibt: "Son education a esté si mauvaise qu'il ne sçait pas l'orthographe du françois et fort mal les caractères." Relations artistiques 1964 (wie Anm. 38) 214.

56 Correspondance 1887 (wie Anm. 55), Bd. I, 335, Bd. 2, 190.

57 Correspondance 1887 (wie Anm. 55), Bd. 2, 153, vgl. auch 62, 90, 109 .

58 Correspondance 1887 (wie Anm. 55), Bd. 2, 24of. 


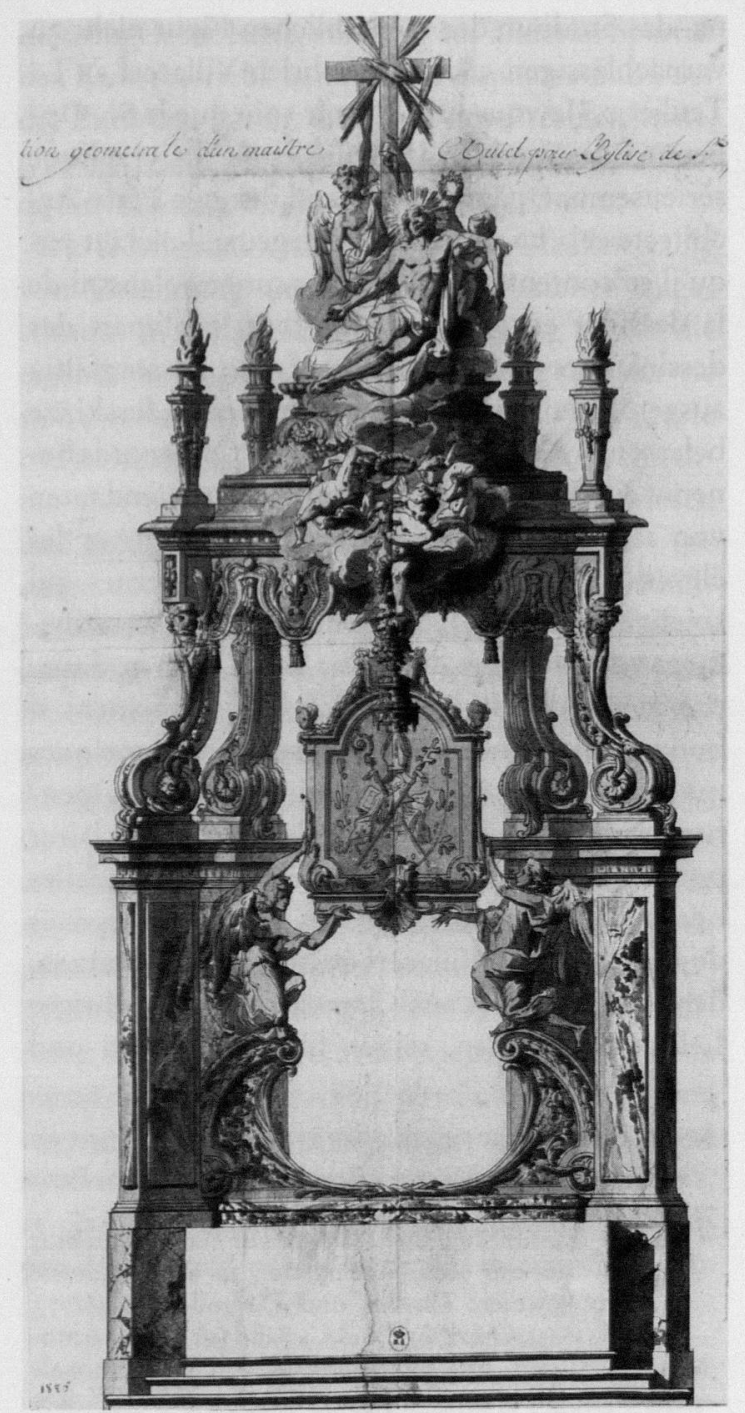

6. Gilles-Marie Oppenord: Hochaltar für St. Germaindes-Prés, Entwurf (Paris, Bibliothèque nationale)

zahlreichen Einzelstudien ziehen sollten, gewiß anders vorgestellt als nur als »divertissement « für Ludwig XIV. Indes kam es wohl nicht einmal dazu. Denn als Oppenord im Sommer 1699 in Paris eintraf, war Villacerf von seinem Amt zurückgetreten, und sein Nachfolger Hardouin-Mansart hatte einen anderen Zeichner, Pierre Lepautre, in seine Dienste genommens?.

Oppenord mußte sich nun auf dem freien Markt nach Aufträgen umsehen. Der inoffizielle Wettbewerb, den Prior de Loo für den Hochaltar von St. Germain-des-Prés veranstaltete, war für Oppenord daher eine willkommene Gelegenheit, die eigenen Fähigkeiten publik zu machen und sich als Zeichner und Architekt zu bewähren. Vielleicht erklärt diese Situation, warum Oppenord mindestens vier verschiedene Projekte zeichnete, mehr als von seinen Konkurrenten Bullet und Hardouin-Mansart/Lepautre bekannt sind, und warum er diese Projekte in beiden gängigen Zeichentechniken, der lavierten und kolorierten bzw. der reinen Federzeichnung vorlegte. Zugleich bestätigt diese Vervielfachung der Entwürfe das Zeugnis, das La Teulière Oppenord 1699 zum Abschluß seines Aufenthalts in Rom ausgestellt hatte: "Il a beaucoup de génie, accompagné d'une fécondité d'imagination et d'une vivacité qui ne sont pas ordinaires, l'un et l'autre secondé par une facilité et habiletté de main surprenante «60.

Oppenords Entwürfe sind nicht datiert. Da sie untereinander durch gemeinsame Motive verbunden sind, müssen sie alle kurz vor der Vergabe des Auftrags an die ausführenden Handwerker und Bildhauer im Juni $1703^{6 \mathrm{I}}$ entstanden sein. Nur zwei Entwürfe sind in Zeichnungen überliefert, die beiden anderen wurden nach Zeichnungen aus Oppenords Nachlaß von Gabriel Huquier im Stich publiziert ${ }^{62}$.

Eines der Projekte zeigt eine von Voluten auf hohen Postamenten getragene marmorne Kuppel, auf der die Skulpturengruppe einer Engelpietà vorgesehen ist (Abb. 6) ${ }^{63}$. Über der Mensa knien zwei weitere Engel; sie tragen das neu anzufertigende Reliquiar für St. Germain. Die Zeichnung ist als "Elevation geometrale d'un maistre Autel pour l'Eglise de St. Germain« betitelt. Damit gibt

59 Kimball 1943 (wie Anm. II), 6 off.

60 Correspondance 1887 (wie Anm. 55), Bd. 2, 453.

6r BN, Ms. fr. 18819, f. 164 (registre des Assemblées des... Prieur et Senieurs...).

${ }^{62} \mathrm{BN}$, Est. Va 269b, fonds de Cotte Nr. $1885 / 86$ recto; Gabriel Huquier: Oeuvres de Gilles Marie Oppenord (= Grand Oppenoird), Taf. LXXVIII, LXXIX; zur Geschichte von Oppenords Zeichnungen vgl. Yves Bruand: Un grand collectionneur, marchand et graveur du XVIIIe siècle, Gabriel Huquier (1695-1772), Gazette des Beaux Arts VI, 37, 1950, 99-II4. 


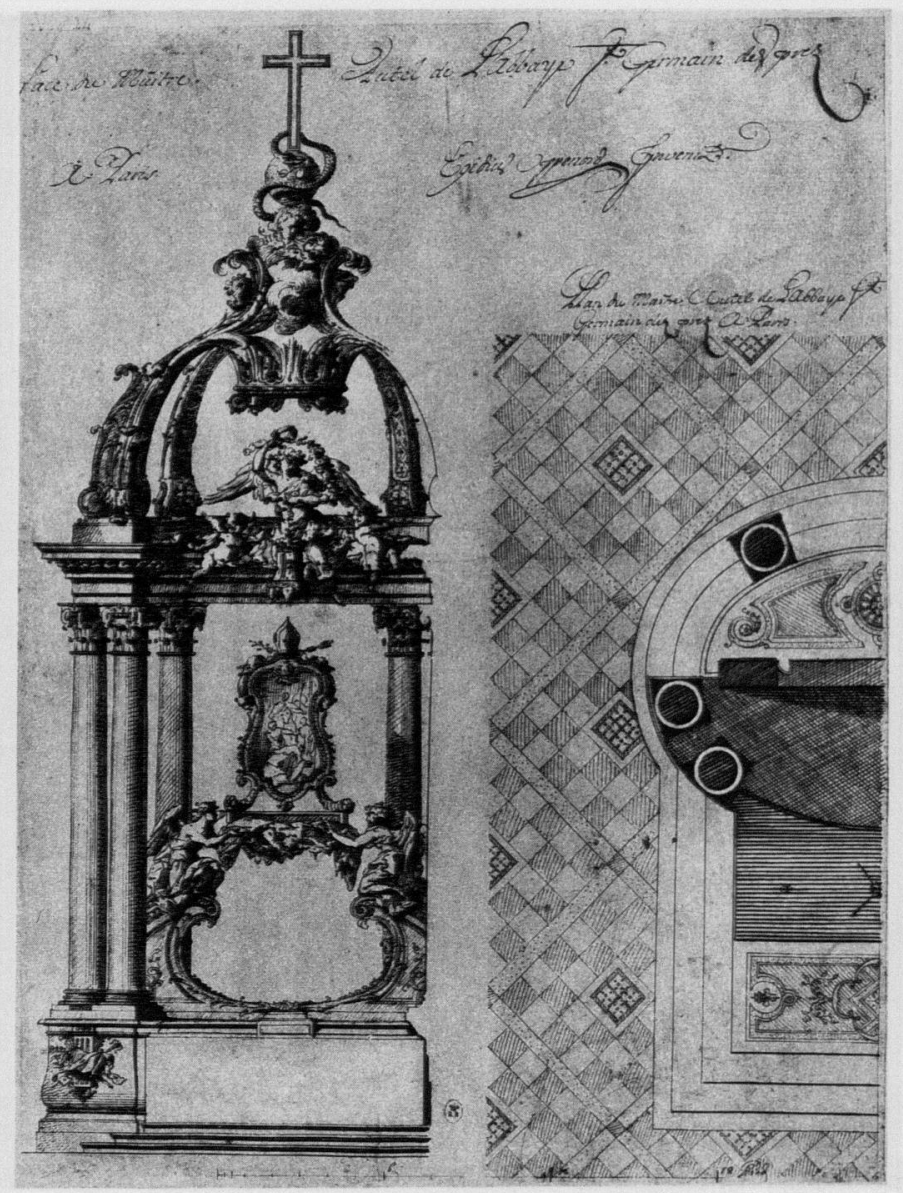

7. Gilles-Marie Oppenord: Hochaltar für St. Germain-desPrés, Entwurf (Paris, Bibliothèque nationale)

sich das Blatt als nur einer von mehreren Vorschlägen zu erkennen. Zudem benennt diese Überschrift die Darstellungsmethode korrekt: Es handelt sich um einen geometrisch aufgenommenen, d. h. orthogonal projizierten Riß. Er ist in Feder ausgeführt, in vielen Farben bunt aquarelliert und grau laviert. Im Vergleich zu Pierre Lepautres Entwurf scheint dieses Blatt zeichnerisch kaum etwas Neues zu bieten; denn Unterschiede im Zeichenstil sind zunächst nur an Einzelheiten zu beobachten. Oppenord zieht fast alle Konturen seiner Baldachinarchitektur mit gleichmäßig spitzer Feder nach. Dabei benutzt er, anders als Lepautre, für alle geraden Stichen ein Lineal. Auf diese Weise betont er den Gegensatz zwischen den scharf geschnittenen Baugliedern und der Dekoration, die ohne Vorzeichnung aus der freien Hand eingetragen ist. Durch die größere Buntfarbigkeit - die Farbskala reicht von violett über lachsrosa und Brauntöne bis zu einem kräftigen Grün - und durch die schärferen Kontraste in der Beleuchtung verleiht Oppenord der Wiedergabe seines Altarprojekts stärkere Plastizität. Plastizität bei Oppenord und die flächigere, einheitlichere Erscheinung bei Lepautre sind jedoch nicht nur durch ein unterschiedliches zeichnerisches Temperament bedingt. In beiden Entwürfen findet so die Herkunft der Motive - bei Lepautre stammen sie 


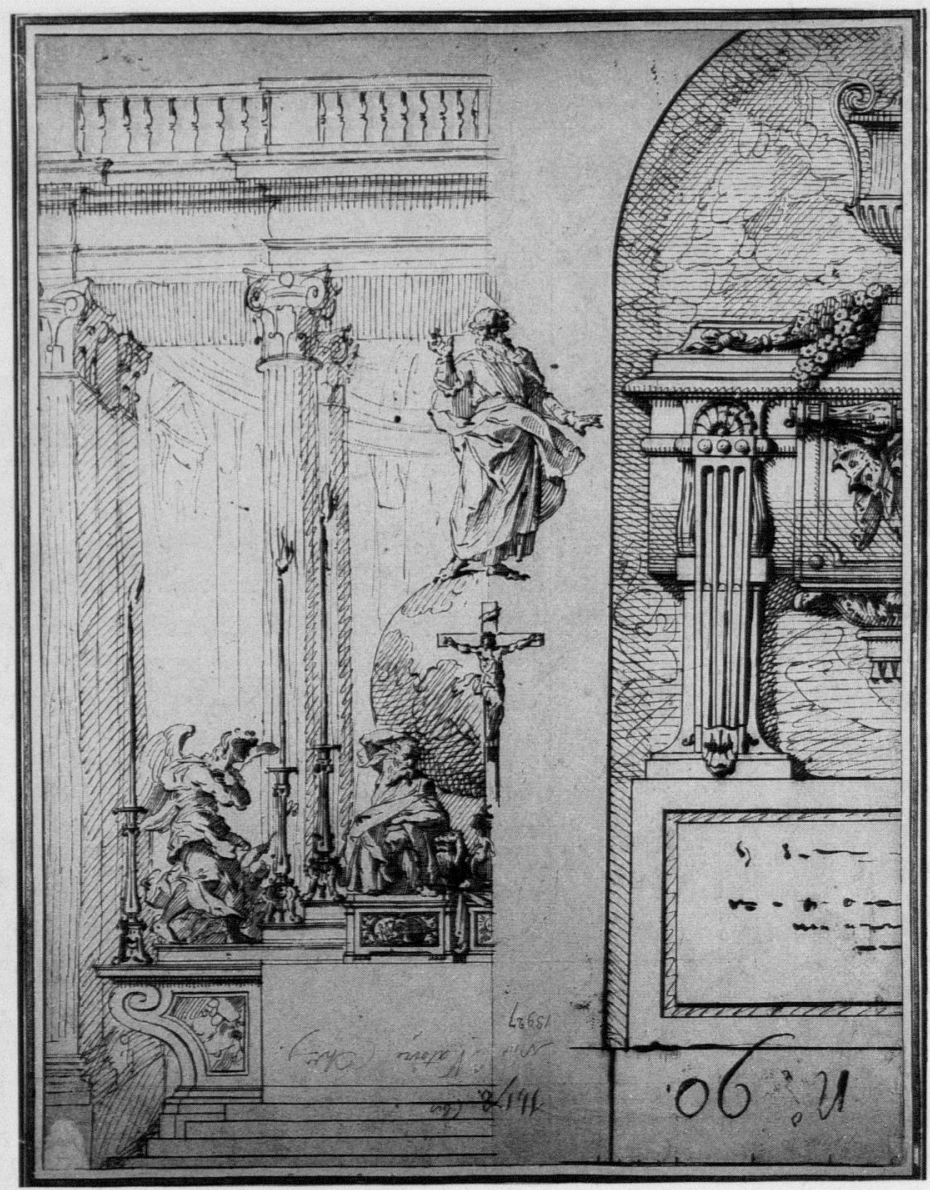

8. Gilles-Marie Oppenord: Hochaltar von S. Giorgio Maggiore/ Venedig und nicht identifiziertes Grabmal, Skizzenblatt (Paris, Louvre)

allein aus der französischen Hofkunst, bei Oppenord kommen Erinnerungen an Borromini und Venezianisches hinzu - ihre adäquate Darstellung. Oppenords Zeichnung, die dem ausgeführten Baldachinaltar am nächsten kommt, ist nur mit der Feder ausgeführt (Abb. 7) 64 $^{6}$. Der orthogonale Aufriß des sechssäuligen Ziboriums und die linke Hälfte seines Grundrisses sind nebeneinander angeordnet. Der Entwurf ist in der Oppenord eigenen Kalligraphie beschriftet und mit »Egidius Oppenord Invenit« signiert. Oppenord scheint sich mit diesem Blatt in die Tradition der Architektenzeichnung zu stellen, die um 1700 noch von Bullet vertreten wird. Indes unterscheidet bereits die Anordnung von Auf- und Grundriß Oppenords Zeichnung von der Bullets. Wie es üblich war, hatte Bullet die beiden obligatorischen Teile eines Entwurfs übereinander plaziert, um ihre Koordinierung zu erleichtern. Oppenord rückte den

${ }_{63}$ BN, Est. Va $269 \mathrm{~b}$, fonds de Cotte Nr. 1885.

${ }_{64} \mathrm{BN}$, Est. Va $269 \mathrm{~b}$, fonds de Cotte Nr. 1886 recto; Germain Brice: Description de la ville de Paris, $1713, \mathrm{Bd} .3$, I3 erwähnt, daß der ausgeführte Altar dem Entwurf nicht in allen Einzelheiten entsprach. Zur motivischen Abhängigkeit dieses Entwurfs von Lorenzo Tedescos Hochaltar in S. Spirito in Sassia (Rom) vgl. Kimball 1943 (wie Anm. II), 102. 


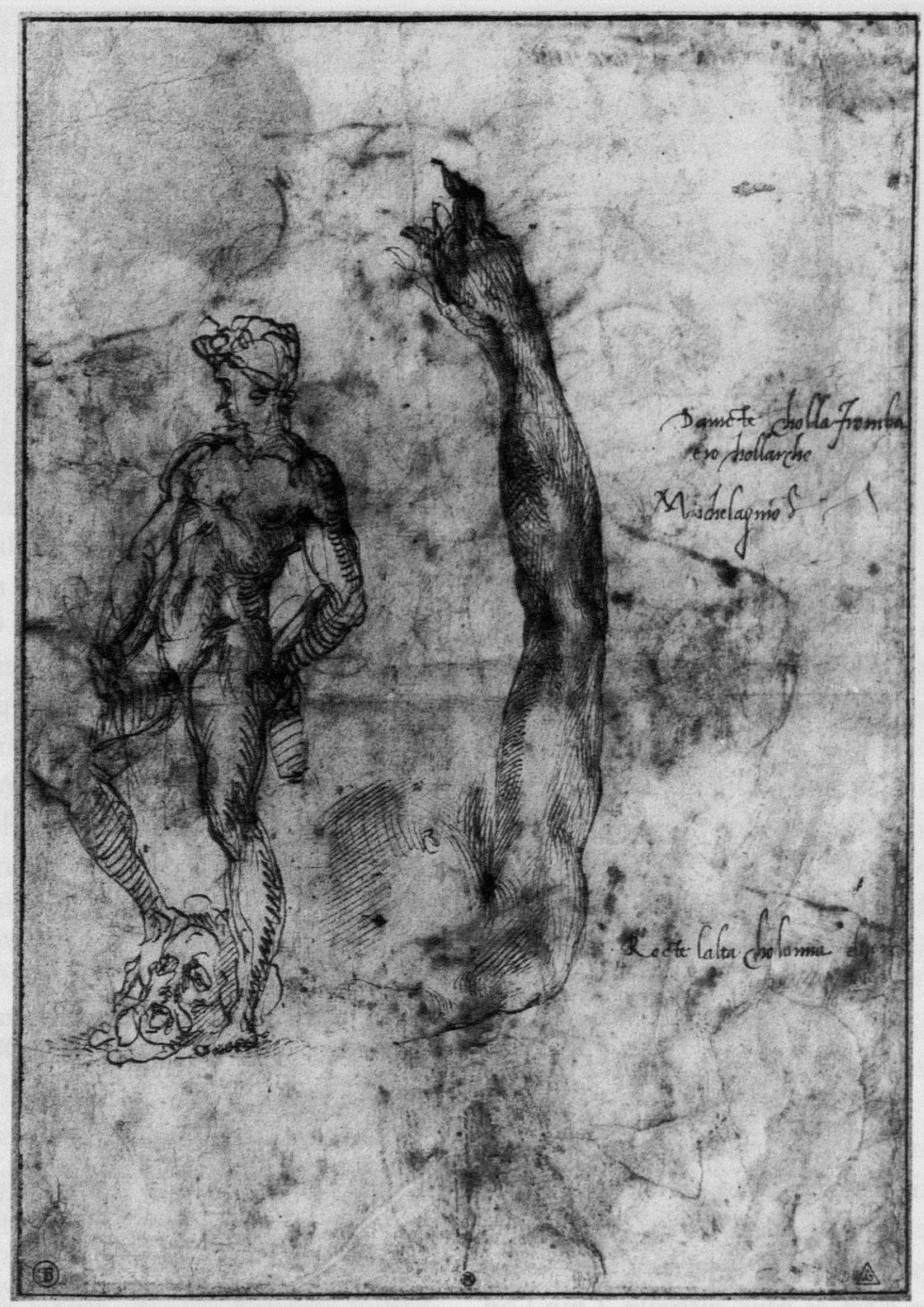

9. Michelangelo: Studienblatt mit David (Paris, Louvre)

Grundriß neben den Aufriß, so wie er auf den Seiten seiner Skizzenbücher Bauaufnahmen verschiedenster Art unterbrachte (Abb. 8) ${ }^{65}$. Immerhin erlaubt im Entwurf für St. Germain der unten angegebene einheitliche Maßstab, die beiden Zeichnungen exakt aufeinander zu beziehen. Von Bullets korrektem, sprödem Umgang unterscheidet sich Oppenords Zeichenstil grundsätzlich. Eine ferne Erinnerung an die Genauigkeit der Architekturzeichnung vermittelt nur die Schraffur der Mensa im Grundriß. Wie im aquarellierten Entwurf bieten die sorgfältig mit dem Lineal aufgerissenen Konturen des Baldachins der freier eingetragenen Dekoration und Skulptur festen Halt.

65 Z. B. das Skizzenbuch im Louvre, R. f. 35698 , Inventaire général des dessins du Musée du Louvre, Ecole française Bd. XII (Nadar-Ozanne), Paris 1975, Nr. 197, 9off., oder das Einzelblatt mit der Aufnahme des Hochaltars von S. Giorgio Maggiore in Venedig, Louvre Nr. 31483 (ebenda, Nr. 196, 90). 
Regelmäßige Parallelschraffuren zur Angabe der Schatten gibt es nicht. Statt dessen sind die Schatten in eiligen Strichlagen über die Architektur gesetzt, und Zick-Zack-Linien markieren die dem Licht ganz abgewandten Partien auf den Säulen. Einige Teile sind so geschwärzt, daß Einzelheiten nicht mehr sichtbar sind, daß also ein Prinzip der Architekturzeichnung, die eindeutige Lesbarkeit, verletzt ist. Oppenord griff eine Möglichkeit der Federzeichnung auf, die er während seines Aufenthalts in Italien ausgiebig hatte trainieren können. Er nutzte diese Technik nicht zu Genauigkeit und Abstraktion, wie es der zeichnerischen Tradition der Architekten entsprochen hätte, sondern zur schnellen Skizze, die zudem seiner »facilité et habiletté de main surprenante « sehr entgegenkam. Skizzenhaftigkeit war es auch, die die Sammler des 18. Jahrhunderts an Federzeichnungen besonders interessierte. Unter den wenigen kritischen Bemerkungen zur Handzeichnung, die aus der ersten Hälfte des 18 . Jahrhunderts überliefert sind, ragt Pierre Mariettes Katalog der Sammlung Crozat mit seinen $»$ Reflexions sur la manière de dessiner des principaux peintres" von $174 \mathrm{I}$ hervor ${ }^{66}$. Die Sammlung Crozat bezog ihren Ruhm u. a. aus dem großen Bestand an Zeichnungen Michelangelos und seines Kreises. Mariette kommentierte die etwa so Blätter, von denen er die besten, d. $h$. seiner Ansicht nach echten, selbst erwarb: "La plus grande partie des dessins... sont à la plume, et hachés dans le goût de la gravure. C'est la manière de dessiner la plus expressive, mais il faut aussi avouer que c'est la plus difficile. Que l'on fasse un faux trait, l'on n'y peut plus revenir.* Mariette betonte jedoch nicht nur die Schwierigkeit dieser Zeichentechnik, sondern würdigte besonders ihre Skizzenhaftigkeit, weil sie ihm im Impetus ihres Strichs und in ihren großen Zügen die Unmittelbarkeit der Übertragung aus der Vorstellung des Künstlers auf das Papier deutlich mache und ihm den Künstler als Schöpfer, als "créateur «, zeige. Michelangelo sei daher »le plus terrible dessinateur qu'il y ait eu " (Abb. 9) ${ }^{67}$.

Der Reichtum an Imagination, die Schnelligkeit, mit der sie sich in der Zeichnung ausdrücke, wird von La Teulière an Oppenord, von Mariette an
Michelangelo gerühmt. Schon diese ganz allgemeinen Übereinstimmungen des Maßstabs im Urteil über Zeichnungen könnten hinreichend erklären, warum die Zeitgenossen die Lizenzen in Oppenords Architekturentwürfen duldeten oder sogar besonders schätzten. Die Parallelen zwischen Michelangelo und Oppenord erschöpften sich jedoch nicht im nahezu identischen Urteil der Connaisseurs des 18. Jahrhunderts über beider Zeichenkunst. Oppenord hat den Vergleich wohl bewußt angestrebt. In Rom hatte er auf dem Kapitol und in der Cappella Strozzi von S. Andrea della Valle gezeichnet, die damals als ein Werk Michelangelos galt ${ }^{68}$. Ob Oppenord schon in Italien Zeichnungen Michelangelos kennenlernte, ist nicht mehr festzustellen. Seit 1715 arbeitete er für Crozat, von 1730 an wohnte er in einem Flügel seines Hauses zur Miete $^{69}$. Er hatte also sicher Zugang zur Sammlung. Zudem war er als Zeichner im Freundeskreis von Crozat akzeptiert: Als einziger Architekt war er mit seinen Entwürfen, wahrscheinlich den Plänen für das Hôtel de Crozat, in der Sammlung vertreten ${ }^{\circ \circ}$, und schon 1715 befand sich ein Band seiner Zeichnungen im Besitz Watteaus ${ }^{\mathrm{r}}$.

66 Pierre Mariette: Description sommaire des dessins des grands maistres d'Italie, des Pays-Bas et de France du cabinet de feu $\mathrm{M}$. Crozat, avec des réflexions sur la manière de dessiner des principaux peintres, Paris ${ }_{1741}$; zu Mariette auch: Le Cabinet d'un Grand Amateur. P. J. Mariette $1694^{-1774}$, Paris 1967.

${ }_{67}$ Mariette 1741 (wie Anm. 66), 1; Mariette 1851 (wie Anm. 49), Bd. 1, 223; zur Bewertung der Federskizze bei den Sammlern des 16. - I8. Jahrhunderts vgl. Julius $S$. Held: The Early Appreciation of Drawings, in Studies in Western Art. Acts of the 2oth International Congres of the History of Art, Princeton 1963, Bd. 3, 82ff.

68 Correspondance 1887 (wie Anm. 55), Bd. 2, 394ff. Der von Oppenord angefertigte Grundriß des Kapitols gelangte später in den Besitz des Architekten Alexandre Brongniart (Alexandre Brongniart, Paris 1986, Nr. 10, 24).

69 Huard 1928 (wie Anm. I2), 312ff.

7o Mariette 174I (wie Anm. 66), 127, Nr. 1065.

71 Carl Nordenfalk: L'An 1715, in: Antoine Watteau ( 1684 - 1715, in: Antoine Watteau ( $1684-1721)$. Le peintre, son temps et sa légende, Genf 1987, 31; zu den heute in Stockholm aufbewahrten Zeichnungen aus dem Besitz Watteaus und dem Problem ihrere Zuschreibung an Watteau bzw. Oppenord: P. Bjurström: Drawings in Swedish Public Collections 4, French Drawings. Eighteenth Century, Stockholm 1982, Nr. 1312 (mit weiterer Literatur). 


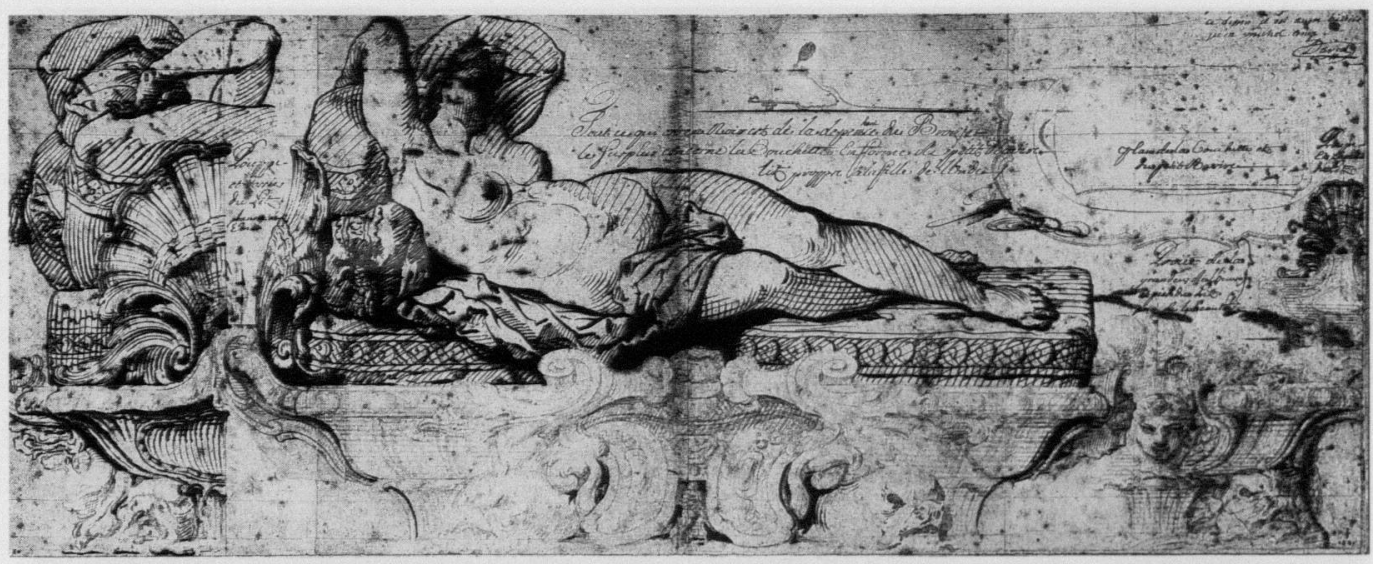

Io. Gilles-Marie Oppenord: Venus, Entwurf (Chantilly, Musée Condé)

Oppenord verrät seine Kenntnis von Skulpturen und Zeichnungen Michelangelos im Entwurf für die Bronzefigur einer Venus und ihr schiffchenartiges Ruhebett (Abb. 10 $)^{72}$. Die lang ausgestreckt liegende Venus, die die Arme über dem Kopf verschränkt, übernimmt in ihrer Haltung Motive von der antiken »Kleopatra oder Giovanni Bolognas Venus mit dem Satyr ${ }^{73}$. In den schweren, muskulösen Formen des Frauenaktes bezieht sich Oppenord auf die Aurora oder die Notte der Medicikapelle, die er wahrscheinlich von seinem Besuch in Florenz, sicher aber durch die Bronzereduktionen in der Sammlung des Bildhauers François Girardon kannte ${ }^{74}$. Die Venus und der Dekor des Ruhe- betts sind in ihren Konturen mit der Feder sorgfältig angegeben. Darüber ist schnell eine parallele und gekreuzte Schraffur gesetzt. Sie dient kaum dazu, Einzelformen herauszumodellieren, sondern will in einem zweiten Schritt den Eindruck von skizzenhaftem Non-Finito erzeugen, den Mariette an Michelangelos Arbeitsweise als Beginn des Zeichnens aus der Imagination beobachtete. Die Angleichung an Michelangelo verfehlte die angestrebte Wirkung nicht. In die rechte obere Ecke des Blatts hat ein gewisser David einen Rat, vielleicht für einen Sammler, geschrieben: 》Je vous engage à garder ce dessin. Il est aussi beau qu'un Michelange $\times 75$.

sollte also in Bronze ausgeführt werden, das Bett bestand aus einem anderen Material.

${ }_{73}$ Eine bronzene Reduktion der »Kleopatra « und ein Exemplar der Venus Giovanni Bolognas befanden sich im Besitz François Girardons. Oppenord zeichnete für die Stichpublikation der Sammlung die Vorlagen der »Galerie«-Architektur. François Souchal: La Collection du sculpteur Girardon d'après son inventaire après-décès, Gazette des Beaux Arts VI, 82, 1973, Iff., Nr. 3, 34; Nr. I54b, S. 71).

${ }_{74}$ Correspondance 1887 (wie Anm. 55), 423; Souchal 1973 (wie Anm. 73), Nr. 50; 5 Iff.

75 Herding 1973 (wie Anm. 72), 2f., identifiziert diesen $\mathrm{Da}$ vid mit Jacques-Louis David. Er habe das Blatt in der Sammlung Reiset gesehen und annotiert. Zumindest die letzte Anname ist nicht zutreffend. David starb 1825 , damals war Fréderic Reiset erst zehn Jahre alt. 


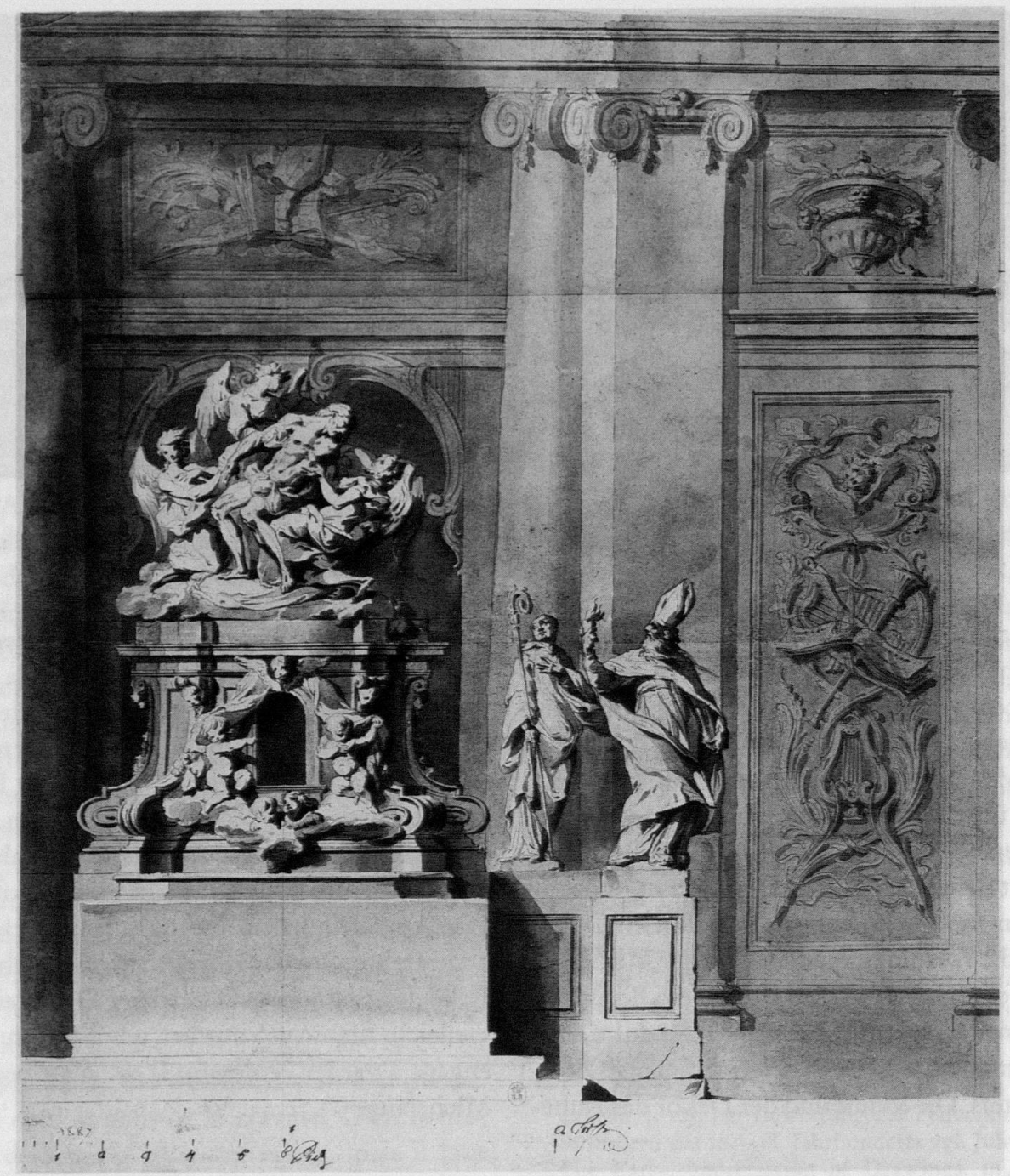

II. Gilles-Marie Oppenord: Hochaltar für St. Germain-des-Prés, Entwurf (Paris, Bibliothèque nationale)

Oppenord wurde spätestens I7Is zum Premier Architecte des Herzog von Orléans, des Regenten, ernannt. Er bekleidete damit an dessen »Hof « dasselbe Amt, das Jules Hardouin-Mansart und anschließend Robert de Cotte am Hof des Königs innehatten; er war nun vermutlich Leiter eines kleinen Baubureaus ${ }^{76}$. Die Ähnlichkeit der Organisationsform in den Bâtiments du Roi und Oppenords Bureau läßt einen nahezu identischen Um- gang mit Zeichnungen erwarten. Die Unterschiede in der Aufteilung der Entwurfsarbeit sind aber so deutlich, daß sie einen Maßstab für die Bewertung von Zeichnung abgeben. Während die Premiers Architectes du Roi die Ausführung der Risse immer den Dessinateurs anvertrauten, zog

${ }^{76}$ Huard 1928 (wie Anm. 12), 316; Le Palais Royal, Paris, 1988, 62 . 


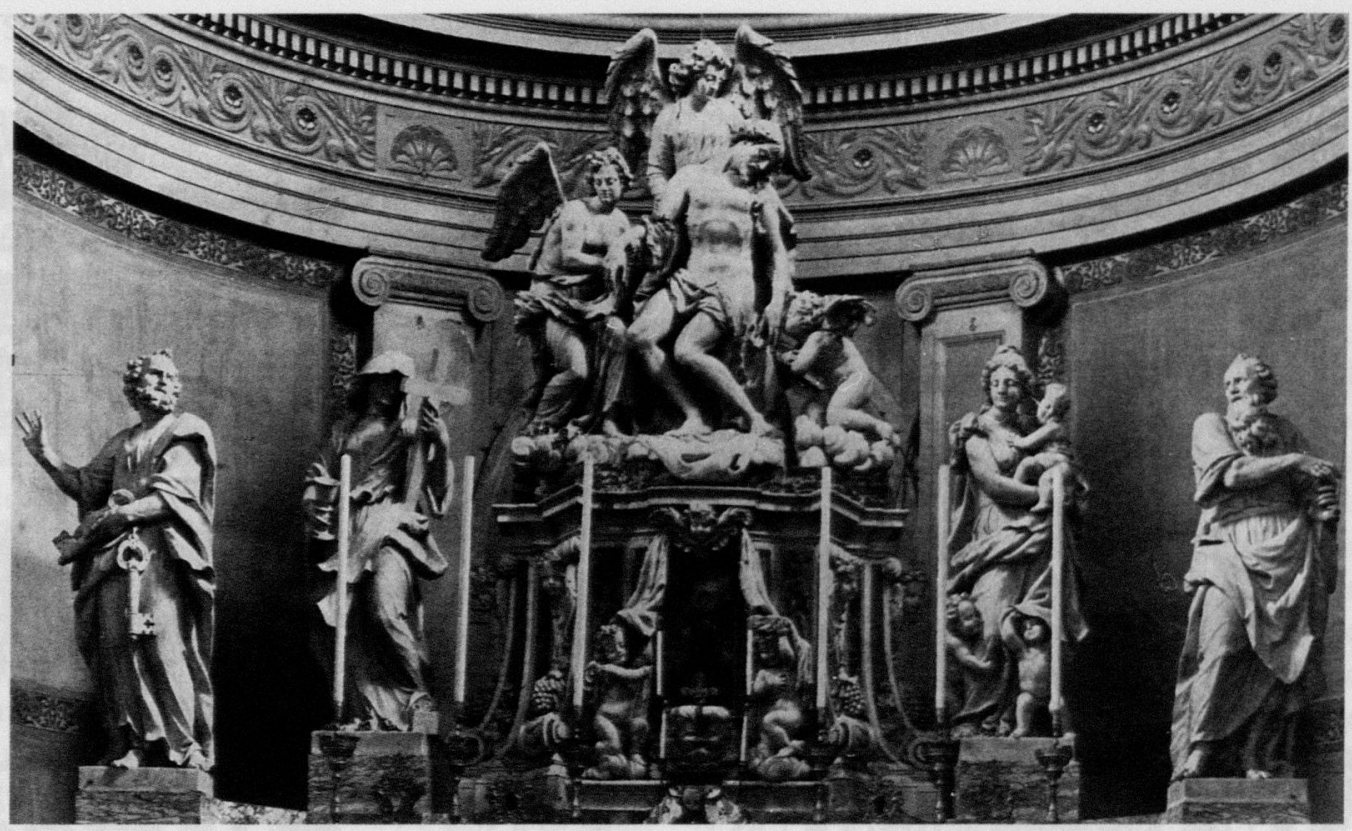

I2. Heinrich Meyring: Hochaltar aus S. Silvestro/Venedig (Nimis, Pfarrkirche)

Oppenord, auch wenn er mit mehreren Projekten beschäftigt war, wohl nie einen Dessinateur heran, sondern zeichnete selbst. Die Entwürfe aus den Bâtiments du Roi und den Bureaus der aus ihnen hervorgegangenen unabhängigen Architekten wie Boffrand und Cartaud waren in der Sorgfalt von Lavierung und Aquarellierung einem einheitlichen Standard angepaßt. Die Zeichner sind nur mit Mühe zu identifizieren 77 und sollten wohl auch nicht identifizierbar sein. Oppenord dagegen entwickelte einen äußerst individuellen, leicht erkennbaren Zeichenstil.

Häufiger als seine Kollegen aus den Bâtiments signierte er die Zeichnungen. Er verwendete dazu meistens seine unverwechselbare Paraphe und machte keinen Unterschied zwischen großformatigen Präsentationsrissen und Einzelstudien ${ }^{7}$. Diese Signaturen meinen im Gegensatz zu den langen Aufschriften auf Zeichnungen aus den Bâtiments, die die vollständigen Titel des Premier Architecte und ein Datum enthalten79, nicht nur die Gesamtverantwortlichkeit für das Projekt, sondern beziehen sich zugleich auf den Entwurf als Zeichnung. Der Unterschied zu den Bâtiments du Roi bestand also nicht nur in einer neuen $\mathrm{Ge}-$ wichtung der zeichnerischen Aufgaben und der größeren Freiheit des Zeichenstils. Die Angleichung an Michelangelo zeigt, daß Oppenord über Zeichnung und ihre »manières« reflektierte. Der Verzicht auf Arbeitsteilung zwischen Architekt und Dessinateur belegt, daß der Zeichnung im

$77 \mathrm{Zu}$ Problemen der Händescheidung zuletzt Bertrand Jestaz, Rezension zu Gallet-Guerne (wie Anm. 3), Bulletin monumental $143,1985,303 f$.

${ }^{78} \mathrm{Z}$. B. Zeichnungen für das Oratoire in der rue St. Honoré, Hélène Couzy: Projets d'Oppenord pour l'achèvement de l'oratoire Saint-Honoré, Gazette des Beaux Arts VI, 80, 1972, 97-IIO.

79 Die ausführlichsten Signaturen tragen die in Ausland versandten Pläne, z. B. der Riß für die Gartenfassade der Würzburger Residenz, Berlin Kunstbibliothek Hdz 4682: "Elevation de la façcade du côte du Jardin du palais de S.A.S. Evesque de Wrtzbourg Duc de franconie, faite par Mr. de Cotte chevalier de L'ordre de St. Michel, Intendant et Premier architecte des Batimens, Jardins arts et Manufactures du Roy de france en 1723: de Cotte (Ekhard Berckenhagen: Die französischen Zeichnungen der Kunstbibliothek Berlin, Berlin 1970, I48). 

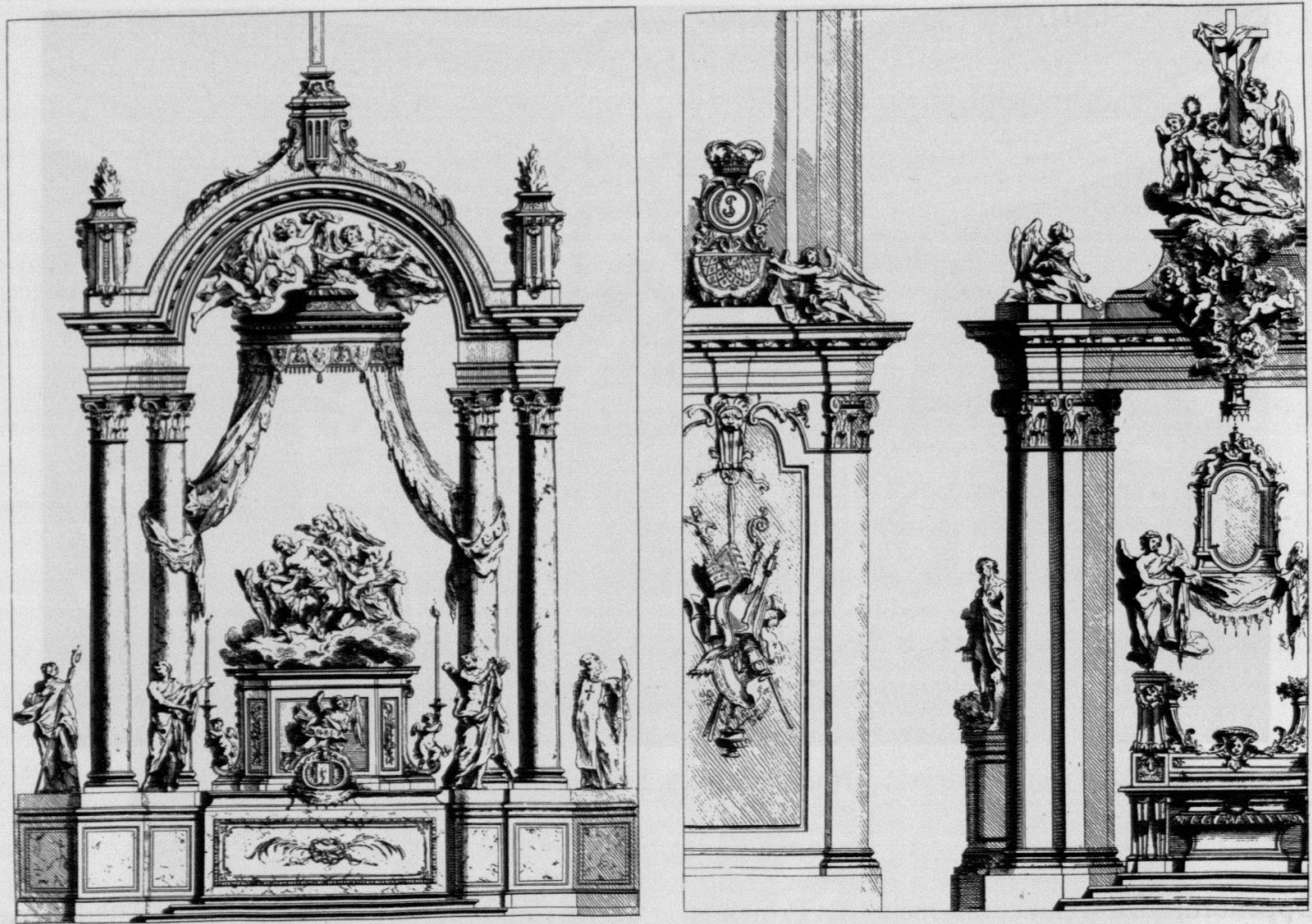

I3. Gilles-Marie Oppenord: Hochaltar für St. Germain-des-Prés, Entwurf (Grand Oppenord Nr. LXXVIII) 14. Gilles-Marie Oppenord: Hochaltar für St. Germain-des-Prés, Entwurf (Grand Oppenord Nr. LXIX)

Vorgang des Entwerfens von Bauten ein eigenständiger Wert zuerkannt wurde.

Mit diesen Feststellungen könnte man sich begnügen. Oppenord erschiene so als ein Vorläufer jener französischen Architekten, die im Kreis um Legeay seit etwa den vierziger Jahren des I8. Jahrhunderts Zeichnung als die beste Gelegenheit verstanden, den Ausdruckscharakter von Baukunst $\mathrm{zu}$ verwirklichen ${ }^{80}$. Oppenord betätigte sich im Bereich der Phantasiearchitektur ${ }^{81}$, die als Gattung von diesen Architekten besonders gepflegt wurde, nutzte Zeichnung aber vordringlich als ein Mittel zum Entwurf realisierbarer Bauten. Er akzeptierte die Bindung der Zeichnung an die Praxis und sah deshalb im Riß das wichtigste zeichnerische Medium des Architekten. Es ist daher nur konsequent, wenn er in diesen Zeichnungen, und nicht in "vedute di fantasia", sein Nachdenken über die
Position des modernen Architekten in der Geschichte der Baukunst deutlich machte.

Einen ersten Hinweis auf diese Aufgabe der Architekturzeichnung enthält ein weiterer Altarentwurf, eine lavierte Federzeichnung aus dem Konvolut der Pariser Bibliothèque Nationale zu St. Germain-des-Prés (Abb. I) ${ }^{82}$. Der Altar steht frei vor einer bis zum Gebälk der ionischen Pilasterordnung sichtbaren Architektur. Über der Mensa erhebt sich ein großes Tabernakel, vor dessen Tür Putti den Vorhang öffnen. Das Tabernakel dient

8o Vgl. Bruno Reudenbach: G. B. Piranesi. Architektur als Bild. Der Wandel der Architekturauffassung des 18. Jahrhunderts, München 1979, bes. 72ff.; Piranèse et les français, Paris 1978.

${ }^{81}$ Sammelband BN, Est. Hd. II; Linfert r93r (wie Anm. 5), Taf. 26-28.

${ }^{82}$ BN, Est. Va 269b, fonds de Cotte Nr. 1887 . 
als Sockel für die Skulpturengruppe einer Engelpietà. Zu Seiten des Altars sind Statuen der Hll. Augustinus und Benedikt vorgesehen, die sich der Pietà in Verehrung zuwenden. Das Konzept dieses Entwurfs, im Tabernakel ein Grab darzustellen, in das die Engel den Leichnam Christi tragen, hat Oppenord nicht selbst entwickelt. Er übernahm es vom Hochaltar in S. Silvestro in Venedig, den der Bildhauer Heinrich Meyring wohl kurz vor Oppenords Venedigaufenthalt vollendet hatte $(\text { Abb. I2) })^{83}$.

Die Funktion der Zeichnung ist nicht leicht $\mathrm{zu}$ bestimmen. Es handelt sich gewiß nicht um eine Bauaufnahme nach Meyrings Altar an seinem ursprünglichen Standort in S. Silvestro. Die ionische Ordnung im Hintergrund und die Dekoration der Wände mit Reliefs sind Oppenords eigene Erfindung, in der er Motive aus seinen römischen Skizzenbüchern frei variiert. Das Figurenprogramm stimmt mit Meyrings Aufbau nicht überein. Oppenord kopiert zwar die Form des Tabernakels mit den Voluten und allen Putti getreu, versetzt aber die steifen Skulpturen der Pietà in eine kreisförmige Bewegung. Durch die schlaglichtartige Beleuchtung der Gruppe, die er vor die dunkel lavierte Arkade plaziert, und die scharfen Kontraste innerhalb des Altaraufbaus arbeitet er das dramatische Konzept heraus, das bei Meyring zugrundeliegt, in der Ausführung dort aber kaum mehr sichtbar ist.

Das Thema der Pietà ist von einem Entwurf für St. Germain-des-Prés bereits bekannt (Abb. 13) ${ }^{84}$. In identischer Form sind die Engelpietà und der Hl. Benedikt des Entwurfs in einer weiteren, nur im Stich überlieferten Zeichnung für St. Germaindes-Prés belegt, die Meyrings Altar um die Interpretation des Tabernakels als Grab Christi reduziert und um ein schrankenartiges Ziborium erweitert (Abb. 14) ${ }^{85}$. Die Zugehörigkeit der vorliegenden Zeichnung zu Oppenords Projekten für St. Germain scheint damit sicher. Auf die Verwirklichung dieses Entwurfs konnte Oppenord aber nicht ernsthaft rechnen. Er mußte wissen, daß St. Germain-des-Prés einen gotischen Chor besaß, in dem sich die hier vorgeschlagene ionische Ordnung nicht einmal als vorgeblendete Architektur ausführen ließ, weil das neue Gestühl unmittelbar vor die Pfeiler gestellt worden war ${ }^{86}$. Es ist daher anzunehmen, daß Oppenord mit diesem Blatt einen Idealentwurf vorlegte, vielleicht um die Gunst des Priors zu gewinnen, bevor er den Auftrag zur Ausarbeitung seiner Projektserie erhielt.

Die Zeichnung weist eine Eigenart auf. Der Sokkel für die Statue des Hl. Augustinus ist an den Kanten bestoßen, seine beiden unteren Steine besitzen große Sprünge. Die Zeichnung gibt also vor, kein Projekt für einen künftigen Altar zu sein, sondern einen Altar und einen Kirchenraum darzustellen, die trotz der Modernität ihrer Formen alt sind. Man könnte diese Andeutung von Spuren der Vergänglichkeit für eine Spielerei des Zeichners halten, die der »facilité et habiletteé« seiner Hand entspringt, oder für einen Vorgriff auf die sich in den nächsten Jahren entwickelnde Gattung des Architekturcapriccios, zu der Oppenord mit einigen Beispielen beitragen wird. Wenn er dann ein verfallenes Grabmal oder Brunnenhaus in einer verwilderten Parklandschaft zeigte ${ }^{87}$, bemühte er sich um die Darstellung einer Vergänglichkeit, in der trotz der Zerstörungen die Monumentalität der Antike gewahrt blieb.

Oppenords Capricci sind zu ihrem größten Teil perspektivische Ansichten von Bauten in Landschaft. Mit dieser Darstellungsmethode verweisen sie auf die Herkunft des Themas; denn Architektur als Ruine blieb bis weit ins 18 . Jahrhundert hinein Gegenstand von Veduten und Prospekten der Maler ${ }^{88}$. In den Zeichnungen und besonders den Stichpublikationen der Architekten wurden die römischen Ruinen gewöhnlich zu vollständi-

${ }_{3}$ S. Silvestro wurde 1839 durch einen Neubau ersetzt. Der Altar befindet sich heute in der Pfarrkirche von Nimis bei Udine. G. Semenzato: La scultura veneta del Seicento e del Settecento, Venedig 1966, 28f., 92 und Abb. 37.

${ }_{84}$ BN, Est. Va 269b, fonds de Cotte Nr. 1885, außerdem Grand Oppenord (wie Anm. 62), Taf. LXXVIII.

8s Grand Oppenord (wie Anm. 62), Taf. LXXIX. ${ }_{86} \mathrm{Vgl}$. Anm. 8.

${ }_{7} 7$ BN, Est. Hd. II; Linfert I931 (wie Anm. 5), Taf. 26c-d. ${ }_{88}$ Einen Überblick geben: John Dean Bandiera: The Pictorial Treatment of Architecture in French Art 1731-1804, Diss. New York 1982; Hubert Burda: Die Ruine in den Bildern Hubert Roberts, München 1972. 
gen Gebäuden oder Gebäudeteilen rekonstruiert und, da man sich um eine korrekt proportionierte Wiedergabe der Architektur bemühte, nach der Methode der orthogonalen Projektion zu Papier gebracht ${ }^{89}$. Wenn in der Regel nicht einmal Ruinen im Riß als Ruine dargestellt wurden, dann ist die Andeutung von noch so geringen Spuren von Verfall, damit vergangener Zeit, in einem Projekt, selbst wenn es sich um einen Idealentwurf handelt, merkwürdig.

Im folgenden möchte ich versuchen, dieses Phänomen in Zeichnungen Oppenords als seinen Beitrag zur Querelle des Anciens et Modernes zu deuten, und zeigen, daß er seine Entwürfe dazu benutzte, die eigene Leistung gegenüber den Alten und den Modernen selbstbewußt herauszustellen. Oppenord hatte während seines Aufenthalts in Italien in der Querelle dezidiert die Partei der Modernen ergriffen. Die alleinige Vorbildlichkeit der Alten, die in Paris seit dem Erscheinen von Charles Perraults »Parallèle des Anciens et Modernes « und Claude Perraults Vitruvkommentar erschüttert war ${ }^{\circ}$, akzeptierte er auch vor den antiken Bauten in Rom nicht mehr.

Mit den Auswirkungen der Querelle auf die Kenntnis der antiken Baukunst mußte Oppenord sich auf eine sehr unmittelbare Weise auseinandersetzen. Wichtiger als die Schriften der Perraults wurde für ihn Antoine Desgodets' Handbuch über die »Edifices antiques de Rome « von $1682^{91}$. Desgodets war 1676 als junger Architekt nach Rom gekommen, um dort im Auftrag der Akademie antike Bauten aufzumessen. Es war das erklärte Ziel seiner Arbeit, die Regeln für die Proportionen antiker Bauten empirisch zu ermitteln und sie zugleich als ein allen Bauten gemeinsames, nachah-

89 Hubertus Günther: Das Studium der antiken Architektur in den Zeichnungen der Hochrenaissance, Tübingen 1988, 37 ff.; 3 I 7 ff.

9o Der Parallèle erschien 1688, der Vitruv 1673, in einer zweiten Auflage $168_{4}$. Zur Querelle vgl. H. R. Jauss: Ästhetische Normen und geschichtliche Reflexion in der Querelle des Anciens et Modernes, in Charles Perrault: Parallèle des Anciens et des Modernes en ce qui regarde les arts et les sciences, München I964; zu ihrem Einfluß auf die Architekturtheorie vgl. A. Hernandez: menswertes Prinzip zu bestätigen. Vielleicht gerade weil die Empirie die Erwartungen nicht erfüllte und sich ein einziges Prinzip nicht finden ließ, glaubte Desgodets an die Proportionen der antiken Architektur als ein »mystère... dont on ignore les causes et usages «92. Desgodets' Buch konnte dazu dienen, die Autorität der Alten in Frage zu stellen, indem es in den Abmessungen der antiken Bauten eine unerwartete Vielfalt und Regellosigkeit aufdeckte. In seinen Einzeluntersuchungen kam Desgodets zu einem neuen Bild der Bauten; denn sein Grundsatz der »Genauigkeit« brachte ihn nicht nur dazu, die Gebäude exakt aufzumessen, sondern sie auch mit bisher nicht erreichter Konsequenz im Riß so darzustellen, wie sie wirklich aussahen: als halb im Boden steckende Ruinen ${ }^{93}$. Die »Edifices antiques " wurden in Paris sicher nicht nur wegen der in ihnen enthaltenen Kritik an den Autoritäten Serlio und Palladio mit Unbehagen aufgenommen 94 . Die Akademie, in deren Auftrag Desgodets gehandelt hatte, vermied es, aus seinen Messungen Konsequenzen für eine Revision der Antike zu ziehen. Das Mißtrauen, gegenüber den ärgerlichen Resultaten zeigt sich auch darin, daß sie noch in den neunziger Jahren nicht als ein fait accompli akzeptiert wurden. Damals erteilte La Teulière als Direktor der römischen Akademie Oppenord den Auftrag, im Rahmen seiner Studien in Rom die von Desgodets angegebenen Zahlen nachzukontrollieren und in Vicenza das dort übliche Fußmaß genau aufzunehmen, in der Hoffnung, so die vielleicht durch falsche Umrechnung entstandenen Diskrepanzen zwischen Palladios »Antichità di Roma« von 1554 und Desgodets »Edifices antiques« auflösen zu können.

Grundzüge einer Ideengeschichte der französischen Architekturtheorie von I500-1800, Diss. Basel 1972, 54 ff.

9 Antoine Desgodets: Les Edifices antiques de Rome dessinés et mesurés très exactement, Paris I682, ${ }^{2} 1697$; Wolfgang Herrmann: Antoine Desgodets and the Académie Royale d'Architecture, The Art Bulletin 40, 1958, 23-53. 92 Desgodets 1682 (wie Anm. 91), Préface (nicht paginiert). ${ }_{93}$ Z. B. Bacchustempel (S. Costanza, 66f.), Titusbogen (178f.).

${ }_{94}$ Zur verzögerten Rezeption der »Edifices antiques * vgl. Herrmann 1958 (wie Anm. 9I), 28 ff. 
Im Gegensatz zu vielen Kollegen bemühte sich Oppenord indes nie darum, an den Diskussionen zu Architekturtheorie und -geschichte mit eigenen Schriften oder Stichpublikationen teilzunehmen. Seine von der Kunstpolitik der Akademie weitgehend unabhängige Position geht daher nur aus den Zeichnungen, zunächst seinen sechs italienischen Skizzenbüchern ${ }^{6}$, hervor. Sie enthalten nur wenige Zeichnungen nach antiken Motiven, meistens nach Grabaltären und anderen Reliefs, die Oppenord wegen ihres Dekors interessierten und deren fragmentarischen Charakter er betont97. Antike Bauten nahm er nicht auf. Das erschien ihm wohl nach Desgodets' Bemühungen, die er mit diesem Übergehen der antiken Gebäude indirekt bestätigt, überflüssigg8. Statt dessen zeichnete er vor allem nach den Modernen, nach Bernini, Borromini und Carlo Fontana. Wie u. a. der Idealentwurf für St. Germain-des-Prés belegt, ließ er auch weniger berühmte Zeitgenossen nicht aus. Die frühen Klassizisten des I8. Jahrhunderts, besonders Charles-Nicolas Cochin, sahen in Oppenord einen der Urheber allen Übels, da er den guten Geschmack durch seine Abkehr von den Alten verdorben habe99. So einfach, wie Cochin es darstellte, war Oppenords Verhältnis zur Antike nicht. Ganz mochte auch er nicht auf ihre Vorbild-

95 Correspondance 1887 (wie Anm. 55), Bd. 2, S. 234f., S. 239 f., S. 390.

${ }^{66}$ Folgende Skizzenbücher sind zur Zeit bekannt:-Berlin, Kunstbibliothek, OZ 81. Berckenhagen 1970 (wie Anm. 79), IIfff., schreibt das Skizzenbuch mit Ausnahme später eingeklebter Blätter (Zeichnungen von Carlo Maratta und einem nicht identifizierten italienischen Architekten) sowie einiger Zeichnungen, die Oppenord auf leere Seiten hinzugefügt habe, François d'Orbay zu. Innerhalb der stilistisch einheitlichen Gruppe, die Berckenhagen für d'Orbay beanspricht, enthält das Buch Zeichnungen nach römischen Monumenten, die erst nach d'Orbays Romaufenthalt (1659/ 6o) entstanden (z. B. f. ${ }_{17} / 18$, Taufkapelle in St. Peter mit Arbeiten Carlo Fontanas von 1695). Für eine $\mathrm{Zu}-$ schreibung dieser Zeichnungen an Oppenord spricht: Das Buch war nachweislich in seinem Besitz. Die Auswahl der aufgenommenen Objekte stimmt mit anderen Skizzenbüchern von seiner Hand überein. Einige Skizzen wurden von Huquier im Petit Oppenord gestochen (Berckenhagen 122). Der Zeichenstil von dünnem Lineament mit blasser Lavierung findet sich auch nach Oppenords Italienaufenthalt noch in seinen Entwürfen, z. B. haftigkeit verzichten, wie die entsprechenden Seiten aus den Skizzenbüchern belegen. Die Antike blieb für ihn ein Maßstab, auf den er seine Entwürfe bezog; ihre Monumentalität sollte zum Thema für seine Architekturphantasien mit antikisch-modernen Mischformen werden.

In einem Sammelband der Bibliothèque nationale in Paris mit "vedute di fantasia» hat sich eine Zeichnung erhalten, die nach Stil und Thema während der italienischen Zeit des Künstlers oder bald danach entstanden sein muß (Abb. I5) ${ }^{\circ 0}$. Ein Haus, ein lichter Pinienhain, ein abgebrochener Obelisk, die nur halb sichtbare Fassade eines ionischen Tempels, das Meer mit Segelbooten im Hintergrund sind - nicht ohne Mißgeschick im Vorund Hintereinander - zum Bild einer mediterranen Landschaft zusammengefügt, wie man es aus Gemälden des 17. Jahrhunderts kennt. In dieser Landschaft steht eine haushohe, schlanke Vase, die durch ihren Dekor mit einer Maske, Festons und Akanthus als antik ausgewiesen ist. Ein Wanderer hat vor dieser Vase Halt gemacht, er blickt zu ihr auf und breitet staunend die Arme aus.

Diese Zeichnung ist nicht ironisch gemeint. Sie nimmt Elemente aus Stichserien auf, die antike oder neu erfundene Vasen als großformatige, das

BN, Est. 254a, fonds de Cotte 2220, Kimball 1943 (wie Anm. II), Abb. 104

- Berlin, Kunstbibliothek, OZ 90 (Berckenhagen 1970 , 164ff.)

- New York, Cooper-Hewitt Museum, Inv. Nr. 1960 IoI, I-62; R. P. Wunder:'The Architect Eye, The CooperHewitt Museum Chronicle 3, Nr. 4, Sept. 1968, 18, Nr. 48. - Paris, Louvre, R. F. 35698 (wie Anm. 65)

- Stockholm, Nationalmuseum, Inv. Nr. 89: 4: A, Kimball 1943 (wie Anm. II), 91, Anm. 107

- ehemals Lyon, Sammlung Abbé Chagny; amerikanischer Privatbesitz, Kimball I943 (wie Anm. Ir), ebenda) - außerdem: Petit Oppenord, Gabriel Huquier: Livre de fragmens d'architecture recueillies à Rome.

${ }_{97}$ Z. B. im Skizzenbuch des Louvre (wie Anm. 65), f. II, I3, 15.

98 Âhnlich ging schon Robert de Cotte vor, als er sich 1689 in Rom aufhielt, Bertrand Jestaz: Le Voyage d'Italie de Robert de Cotte. Etude, édition et catalogue des dessins, Paris 1966, 183, 210.

${ }_{99}$ Charles-Nicolas Cochin: Lettre à M. l'Abbé $* \% *$,.., Mercure de France, Febr. 1755, $153 \mathrm{f}$.

${ }^{100} \mathrm{BN}$, Est. Hd. 11, fonds de Cotte Nr. 1888. Das Blatt ist von fremder Hand falsch datiert und lokalisiert: "Lugduni $1698 \%$. Oppenord hielt sich 1698 noch in Italien auf. 


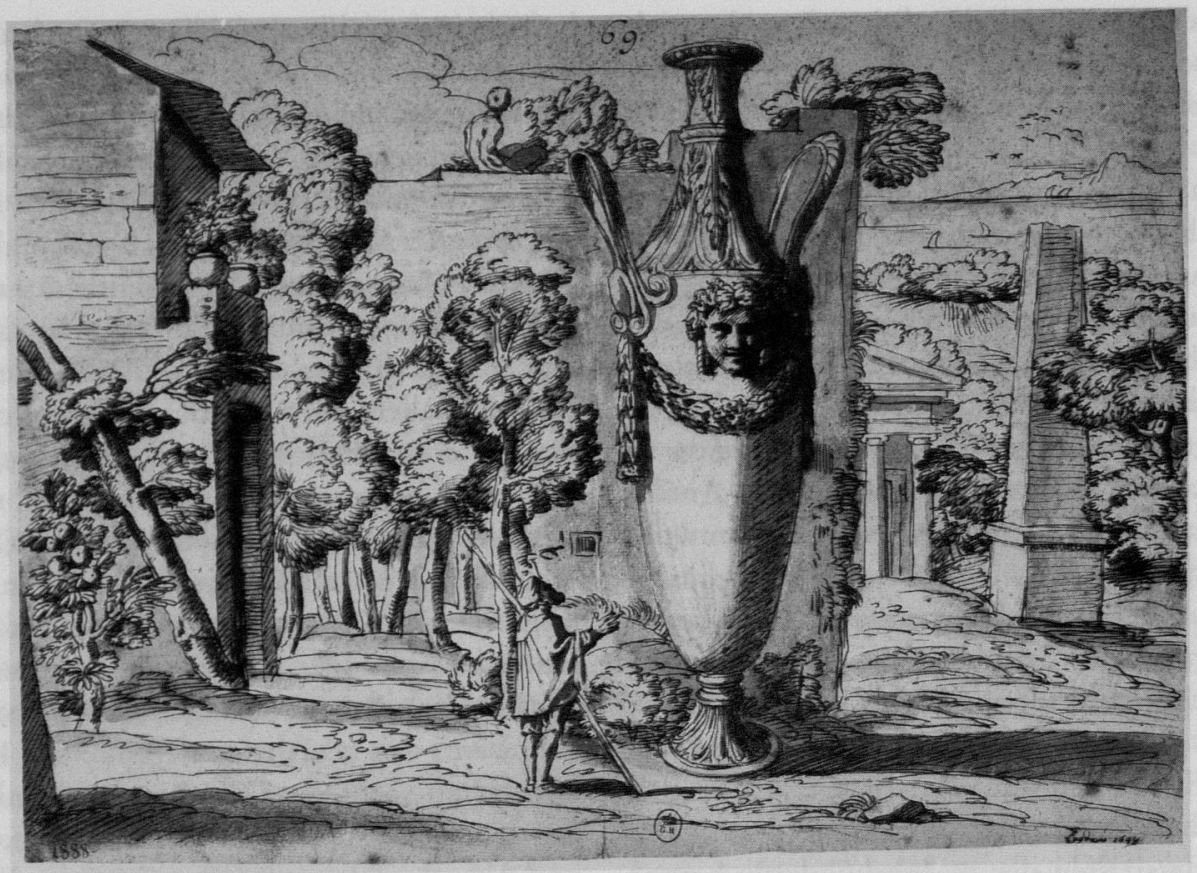

I5. Gilles-Marie Oppenord: Landschaft mit Vase (Paris, Bibliothèque nationale)

ganze Blatt ausfüllende Vorlagen verbreiteten. Jacques Damery war 1657 wohl einer der ersten Ornamentstecher, der die Vasen monumental in den Vordergrund einer Landschaft plazierte (Abb.

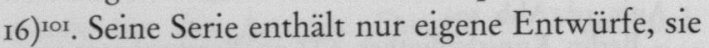
heißt aber »Vases antiques«. Dementsprechend stehen die großen Gefäße vor einer antikischen Landschaft. Die Staffagefiguren geben den Maßstab für die Monumentalität der Vase ab, sie sind in antikischer Nacktheit oder Gewandung dargestellt und verstärken so den im Titel der Serie benannten Anspruch des Stechers: Eigenes, Modernes, als antik zu verkaufen ${ }^{\text {102. }}$.

Oppenords Vase will keine Vorlage sein. Sie füllt das Blatt nicht aus und kann daher aus der umgebenden Landschaft ihre Größe beziehen. Der Wanderer ist kein Zeitgenosse der Vase, sondern ein Moderner. Er kontempliert nicht, wie es die Alten vor der Pseudo-Antike Damerys oder Cosimo III.als Moderner vor der echten Antike der Medici-Vase bei Stefano della Bella tun (Abb. 17) ${ }^{103}$, sondern reagiert aktiv in seiner Überra- schung. Aus der Zeichnung spricht eine unbefangene Haltung vor der Antike, die das große Selbstbewußtsein des jungen Architekten erkennen läßt. Von Füßlis Verzweiflung des Künstlers vor der Größe der Antike hat die Zeichnung nichts ${ }^{104}$.

Damerys Absicht war es, die eigenen Erfindun-

101 Werner Oechslin/Oskar Bätschmann: Die Vase, Zürich, 1982, Nr. Nr. 173a-e. Die Serie stammt aus den soer Jahren des 17. Jahrhunderts.

${ }_{02}$ Der im Zwiespalt von Titel, Landschaft und Staffage sowie der Vase als Gegenstand eines ornamentalen Vorlageblatts angelegte Wettstreit mit der Antike ist bei Oechslin 1982 (wie Anm. I0I), I48ff. und Nr. 173, nicht verstanden. Auf diese Art des Wetteiferns verzichten Jean Lepautres Vasenserien »à la Romaine« (Nr. 180), "inventé de nouveau « (Nr. 182) oder Fischer von Erlachs Vasen aus dem »Entwurff einer Historischen Architektur« (Nr. 186) mit ihren Hintergründen aus moderner (Garten-)Architektur.

${ }_{103}$ Oechslin/Bätschmann 1982 (wie Anm. IOI) Nr. 228. Das Blatt entstand 1656 .

104 Gert Schiff: Johann Heinrich Füssli I74II825, Zürich 1973, Nr. 665; zum Bedeutungswandel der Ruinen vgl. Burda 1967 (wie Anm. 88), roff., unter Bezug auf die Querelle Reudenbach 1979 (wie Anm. 80), I2ff., S. 6 off. 
gen als Antiken auszugeben, indem er sie in eine antikische Umgebung versetzte und mit einer gewissen Inkonsequenz auf einigen Blättern so zeigte, wie man Antikes vor allem aus Veduten kannte: Mit eben den Altersspuren - Sprüngen und angestoßenen Kanten - am Sockel, die Oppenord dem Sockel seines Hl. Augustinus im Entwurf für St. Germain-des-Prés geben sollte. Wahrscheinlich verfolgte Oppenord mit der Übernahme dieses Tricks in die Architekturzeichnung dasselbe Ziel. Er versuchte, seinen Entwurf, der in den Motiven ganz auf Modernem beruhte und zudem einen christlichen, also gewiß nachantiken Altar zeigt, im Wert der antiken Architektur anzugleichen. Angestoßene Kanten und Sprünge im Stein erhielten demnach die Aufgabe, nobilitierend auf das Altertum zu verweisen. Oppenord mutete nun dem Auftraggeber zu, das Abstraktionsniveau der Architekturzeichnung, das in der Methode der orthogonalen Projektion angezeigt war, zu erkennen und dargestellte Schäden nicht als künftigen Verfall eines noch nicht existenten Werks zu lesen ${ }^{\text {os. }}$. Er nahm also im Medium der Zeichnung für sich selbst in Anspruch, was Serlio I540 nur Bramante zugestanden hatte, als er ihn in den Holzschnitten im dritten Buch seines Traktats unter die Alten aufnahm, ohne aber Bramantes Tempietto als ruinös und ebenso gealtert wie das Kolosseum darzustellen ${ }^{106}$.

Indes war Oppenord in der Anwendung seiner zeichnerischen Mittel inkonsequent. 1718-2I baute

ros Mir ist nur ein Beispiel dafür bekannt, daß ein Architekt seine eigenen und antike Bauten (bzw. Rekonstruktionen) gleichermaßen mit der Wiedergabe von Bauschäden veröffentlichte und so eine Angleichung vornahm: Andrea Palladios Rekonstruktionen antiker Bauwerke in Daniel Barbaros Vitruv ('I556, vgl. E. Forssman: Palladio e Daniele Barbaro, Bollettino del Centro internazionale di Studi di architettura Andrea Palladio 8, 1966, 68ff.) und Rekonstruktionen sowie eigene Villenentwürfe in den Quattro libri dell'architettura 1570 (z. B. Buch II, 32: Dell'Atrio testugginato; 68: Villa Sarego in Miega) Die Vorlagen für die Holzschneider enthalten keine Darstellung von Bauschäden (zur Entstehung der Quattro libri vgl. E. Forssman, in: A. Palladio: I quattro libri..., ND Hildesheim 1979, XVff.). In gezeichneten Präsentationsrissen findet sich die Darstellung des nicht als Ruine geplanten Baus als Ruine bei William Chambers: Mausoleum für den Prinzen von Wales 175I/52 er für den Regenten Philippe d'Orléans im Palais Royal in Paris einen doppelgeschossigen Salon, der als Kopfraum zweier Enfiladen besonders stattlich ausfallen sollte und daher über Jacques Lemerciers Straßenflucht von ca. 1648 hinausragte ${ }^{\mathrm{rO}}$. Für diesen Salon sind zwei Präsentationsrisse überliefert. Der Aufriß zur Rue de Richelieu zeigt, wie Oppenords neuer Salon auf einer eleganten, weit gespannten Trompe in die Straße hinausragt (Abb. 18) ${ }^{108}$. Die Mauern der alten Bauteile sind mit so vielen Schäden am Stein und bröckelndem Putz dargestellt, daß die neue kühne Konstruktion in ihrer Unversehrheit davon deutlich absticht. Dieselbe Kennzeichnung von alten Quadern und neuer Architektur enthält auch der Schnitt (Abb.

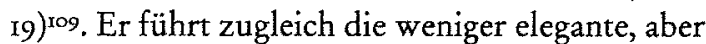
realisierbare Lösung vor, nach der der Erker auf Konsolen und dicken Balken in die Straße hinausgebaut wurde.

So baufällig, wie es hier aussieht, war dieser Teil des Palais Royal nach den etwa 80 Jahren seines Bestehens gewiß nicht. Ein unbefangener Betrachter oder ein kritischer Architekt hätte sogar fragen können, wie Oppenord sich die statische Sicherheit seines zweigeschossigen Aufbaus auf Mauern in so desolatem Zustand vorstellte. Als Vedute des Palais Royal waren diese Risse aber nicht angelegt. Sie sollten vielmehr gegenüber dem Regenten die Qualität des Neuen im Vergleich zum Alten besonders deutlich hervorheben und damit eine der

(London, Victoria and Albert Museum) und York House 1760 , London, Royal Institute of British Architects; vgl. John Harris: Le Geay, Piranesi and international Neoclassicism in Rome, 1740-1750, Festschrift Rudolf Wittkower, London 1967, Bd. I, 195f., Abb. 34; RIBA, London, Catalogue of Drawings Collection, London 1972, Abb. Io.

ro6 Sebastiano Serlio: Il terzo libro... nel qual si figurano, e descrivano le antiquità di Roma, Venedig 1540, Günther 1988 (wie Anm. 89), Abb. 31 .

107 Palais Royal 1988 (wie Anm. 76), 13, 62f.; f. Kimball: Oppenord au Palais Royal, Gazette des Beaux Arts VI, I5, 1936, 113-I17.

${ }_{108}$ Ellevation de la face exterieure du Sallon sur la rue de Richelieu, Privatbesitz; Palais Royal 1988 (wie Anm. 76), Nr. 43, 7if.

rog Coupe du Salon d'alignement à l'Enfilade du grand Appartement du Palais Royal, New York, Cooper-Hewitt Museum, Kimball 1936 (wie Anm. 107), Abb. 2. 


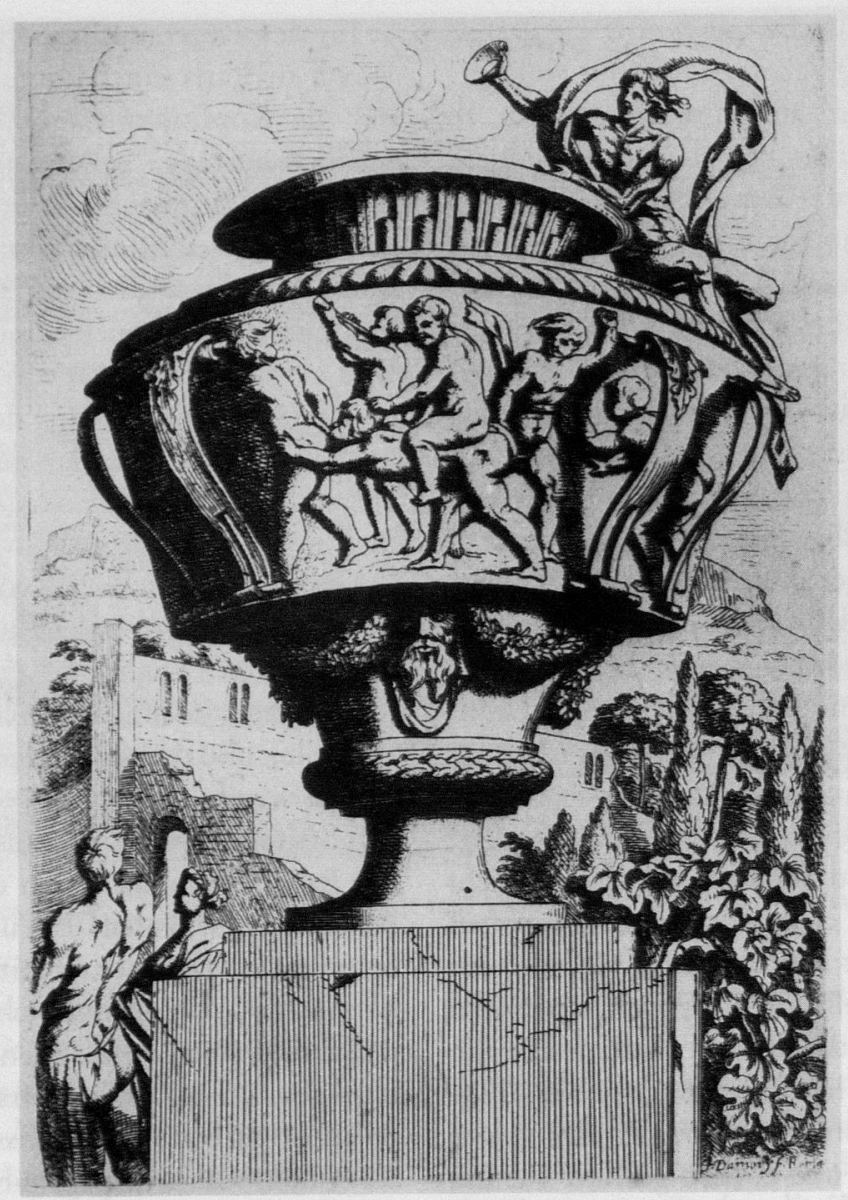

I6. Jacques Damery: ,Vase antique

Hauptaufgaben der Präsentationszeichnung, den Auftraggeber zu überzeugen, erfüllen. Darüberhinaus wird sichtbar, daß Oppenord jetzt im Bewußtsein eigener Fähigkeiten Modernes, nämlich Jacques Lemerciers Palais Royal, mit denselben zeichnerischen Kunstgriffen wiedergab, die er sonst vor allem in seinen Capricci auf Antikes oder Pseudo-Antikes anwendete. Angestoßene Kanten und Sprünge im Stein haben jetzt weniger verweisenden als abbildenden Charakter. (Pseudo-)Antikes und Modernes werden so als gleichermaßen Vergangenes beschrieben, von dem sich das eigene Projekt optimistisch abhebt ${ }^{\text {ro. }}$.

Oppenord hatte als Architekt dieses Insistieren auf der eigenen Leistung nötig, denn er war ein schlechter Statiker. Der Salon des Palais Royal

Iro Oppenords Selbstbewußtsein gegenüber den Autoritäten unter den Modernen wird auch in einer Studie für ein Kapitell deutlich, die durch eine Beischrift erläutert ist: »Composé Selon Scamozzi et moy dont je me sert [!] ordinairement « (Paris, Ecole des Beaux-Arts, Couzy 1972 (wie Anm. 78) IO4, Abb. 8). Einen sehr viel systematischeren Vergleich zwischen alter, moderner und zeitgenössischer Architektur werden Fischer von Erlach im "Entwurff einer Historischen Architektur « (172I) und Meissoñier in den Übersichtstafeln seines »Parallèle général des édifices considérables depuis les egyptiens, les grecs, jusqu'à nos derniers modernes « vornehmen, Dorothea Nyberg ( $\mathrm{Hg}$.): Oeuvre de juste Aurèle Meissonnier, New York 1969 , $29 \mathrm{ff}$. 


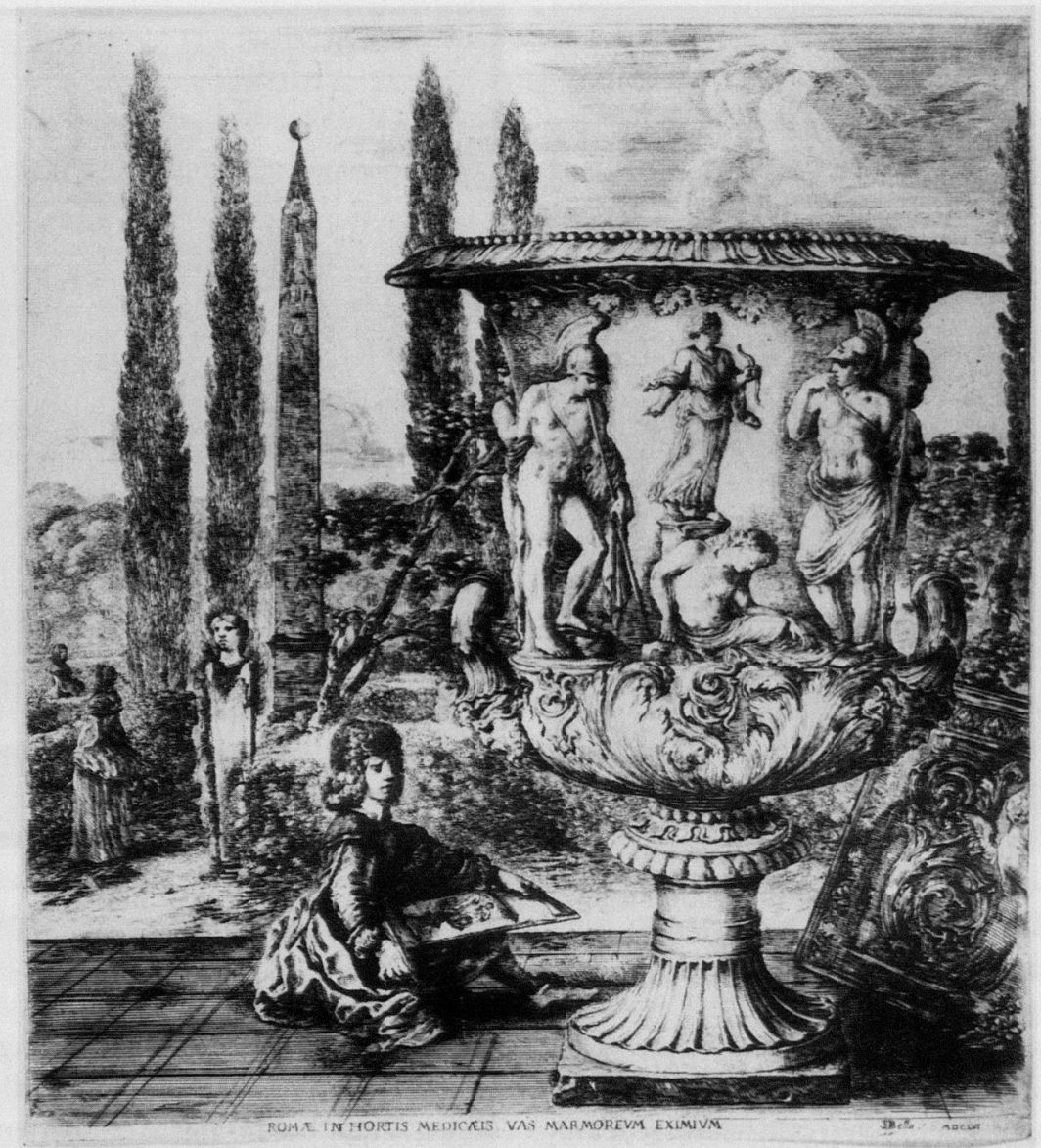

17. Stefano della Bella: Cosimo III. zeichnet die Medicivase

hielt zwar auf seinen Konsolen, die aber im Vergleich zu den großen stereometrischen Kunststükken anderer französischer Architekten keine

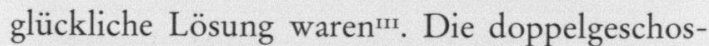
sige Galerie des Hôtel Crozat brach 1725 zusammen, und 1731 mußte der Vierungsturm von St. Sulpice abgerissen werden, bevor er die Gewölbe der Kirche zum Einsturz brachte ${ }^{\mathrm{HI}}$. Oppenord war einer der ersten Architekten des 18. Jahrhunderts, die keine Ausbildung auf dem "chantier" erfuhren, dafür aber an der Académie studierten. Dennoch verstand er sich selbst als Architekt im Sinne des Baumeisters und erhielt als solcher seine Aufträge. Zugleich schöpfte er die Möglichkeiten der Architekturzeichnung, ihrer graphischen Techniken und ihrer Darstellungsmethoden, deren traditionelle Anwendung er zunächst gelernt hatte, weiter aus als nur zur Präsentation von Bauprojekten. Er hatte erkannt, daß Entwurfszeichnungen im Werk eines Architekten neben ihrer Ausrichtung auf das Bauen eigenen Wert besitzen konnten.

mi Anatole de Montaiglon (Hg.): Brevets de la Calotte relatifs... à l'architecte Gilles-Marie Oppenord, Archives de l'Art français, 2e série 2, 1862, 90 off.

${ }^{112}$ Huard 1928 (wie Anm. II), $317 f f .$, zu St. Sulpice auch: E. Malbois: Oppenord et l'église Saint-Sulpice, Gazette des Beaux Arts VI, 9, 1933, 34-46; Couzy 1972 (wie Anm. 78), Iorff. 

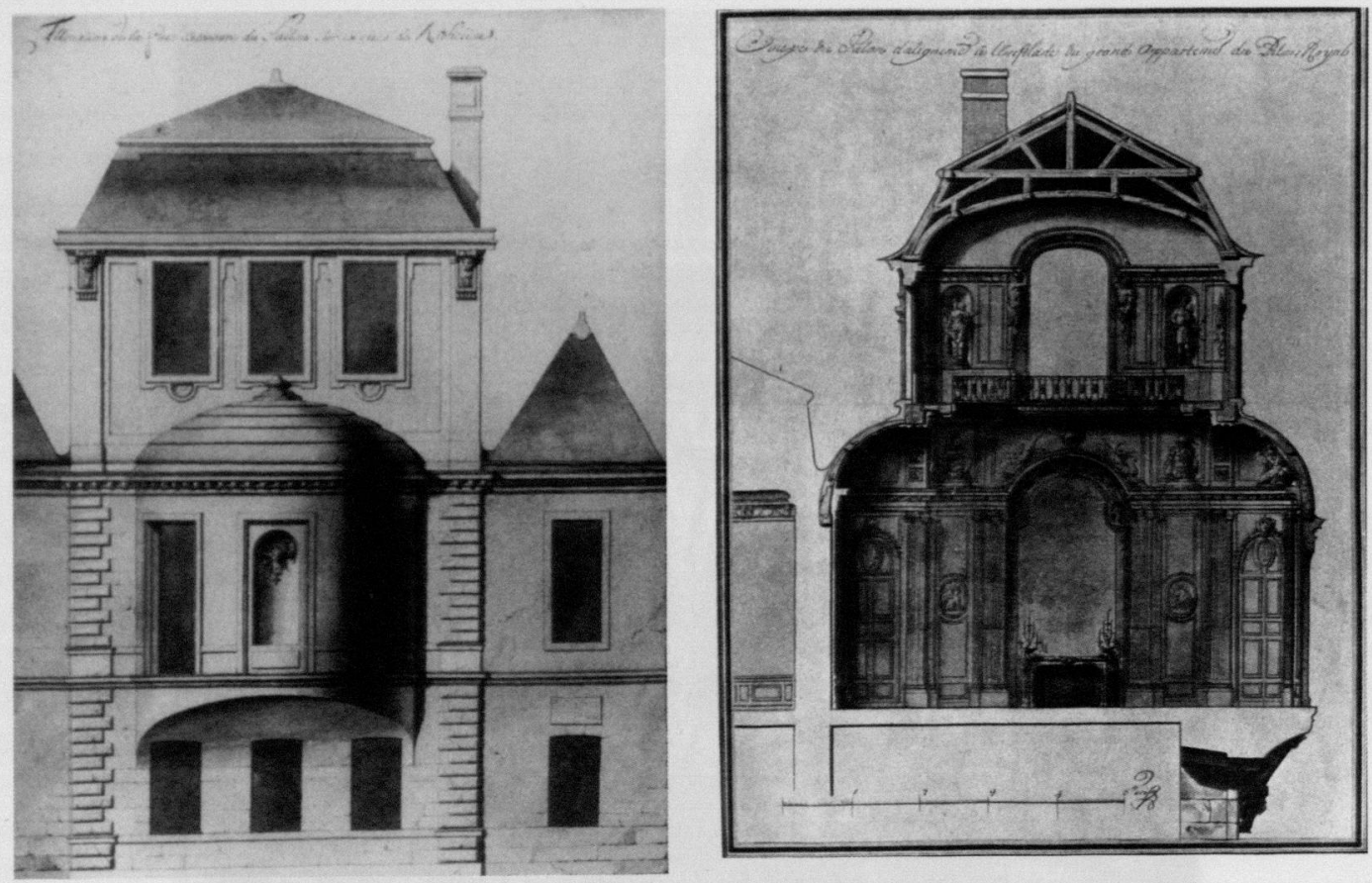

18. Gilles-Marie Oppenord: Salon des Palais Royal, Entwurf (Privatbesitz)

19. Gilles-Marie Oppenord: Salon des Palais Royal, Entwurf (New York, Cooper-Hewitt Museum)

Die zeichnerischen Fähigkeiten Oppenords konnten die Zeitgenossen, die seine Mißerfolge im Bauen miterlebten, nicht recht würdigen. 1725 amüsierte man sich über die Geschwindigkeit, mit der der Zahn der Zeit an Oppenords Bauten seine Spuren hinterließ. Zum Einsturz im Hôtel Crozat sagt ein Pamphlet:

\section{Un riche et noble cabinet}

Sur un fondement si solide,

Que le temps, ce glouton avide,

N'a pas attendu les dix ans

Pour lui faire sentir ses dents ${ }^{\mathrm{II} 3}$.

Erst gegen Ende des Jahrhunderts hatte sich in Frankreich der Architekt als Zeichner etabliert, konnten Architektur und Zeichnung ein und dasselbe sein. 1787 schrieb Dezallier d'Argenville in seinen Viten berühmter Architekten über Oppenord: »On estime fort ses dessins à la plume et à l'encre de la chine: ils ont fait seuls sa grande réputation. Leur touche hardie et séduisante empêchoit qu'on ne s'aperçût qu'ils ne faisoient plus le même effet dans l'exécution. L'auteur en étoit très-jaloux, et savoit en tirer un fort bon parti «II4.

${ }_{113}$ Montaiglon I862 (wie Anm. III), 9I.

${ }^{14} 4$ Dezallier d'Argenville ${ }_{1787}$ (wie Anm. 53), 439.

Aufnahmen: 1, 2: Nationalmuseum, Stockholm. - 3, 6, 7, II, 15: Bibliothèque nationale, Paris. - 4, 5: Archives nationales, Paris. - 8, 9: Musée du Louvre, Paris. - 10: Giraudon. - 13, 14, 19: Kunstgeschichtl. Institut, Freiburg. - 16, 17: Museum für Gestaltung, Zürich. - 12: nach Semenzato (wie Anm. 83). - 18: nach Palais Royal (wie Anm. 76). 